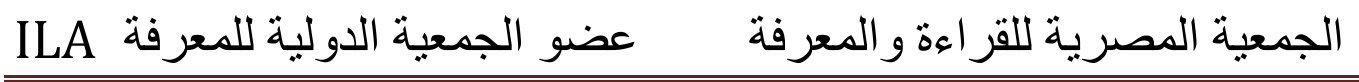

\section{دور الادارة الالكترونية في تطوير اداء القيادات المدرسيه في تعليم محافظة ينبع بالمرحلة الثانوية}

\author{
إعداد \\ أ / عبدالله سلامة ضبيعان السناني \\ ماجستير ادارة وتخطيط تربوي \\ ادارة تعليم محافظة ينبع
}




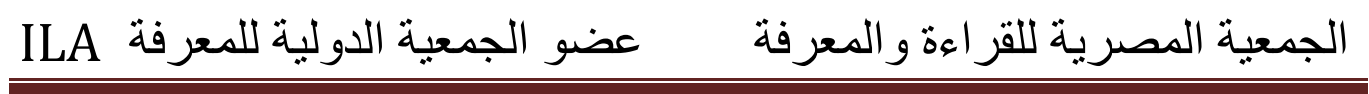




\section{الجمعية المصرية للقر اعة و المعرفة عضو الجمعية الدولية للمعرفة ILA}

\section{دور الادارة الاككترونية في تطوير اداء القيادات المدرسيه في تعليم محافظة ينبع بالمرحلة الثانوية}

مستخلص الاراسة هدفت الدراسة الي التعرف علي دور الادارة الالكترونية في تطوير اداء القيادات المدرسيه

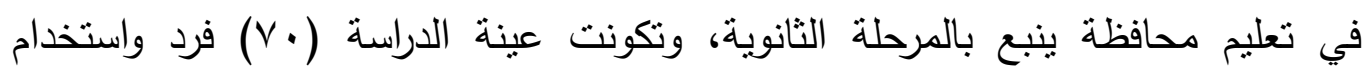
الباحث المنهج الوصفي، ونوصلت نتائج الدراسة الي ان تطبيق الإدارة الإلكترونية في

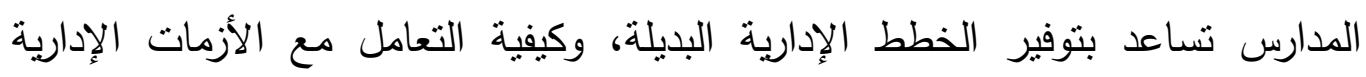
والبيئية المستجدة التي نواجه الإدارة بشكل مفاجئ، كما إن استخدام الإدارة الإلكترونية الإنية

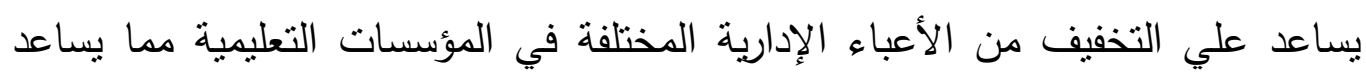

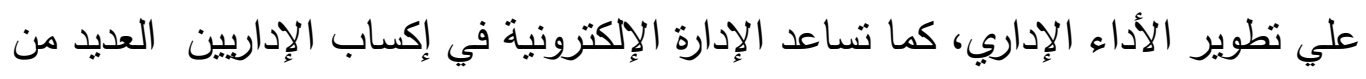

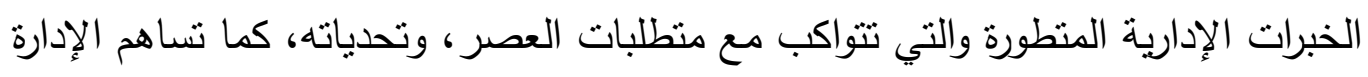

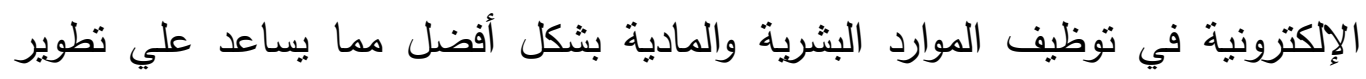

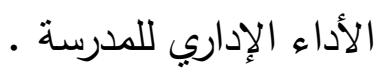




\section{The role of electronic administration in developing the performance of school leaders in the education of Yanbu Governorate at the secondary level}

\section{abstract.}

The study aimed to identify the role of electronic management in developing the performance of school leaders in the education of the province of Yanbu at the secondary stage, and the study sample consisted of (70) individuals and the researcher used the descriptive approach, and the results of the study concluded that the application of electronic management in schools helps provide alternative administrative plans, and how to deal With the sudden administrative and environmental crises facing the administration, the use of electronic management helps to alleviate the various administrative burdens in educational institutions, which helps to develop administrative performance, and electronic management helps to provide administrators with many advanced administrative experiences that are in line with the requirements of the times And its challenges, as the electronic administration contributes to better employing human and material resources, which helps in developing the school's .administrative performance 


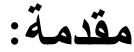

أصبحت التطورات السريعة في شتى مناحي الحياة سمة هذا العصر؛ وذلك الكيات

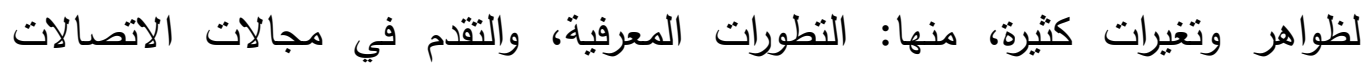

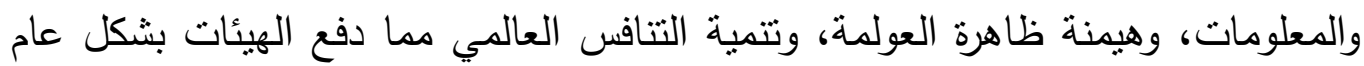
والجهات التعليمية على وجه الخصوص إلى ضرورة مواجهة هذه التحديات، مما فرض

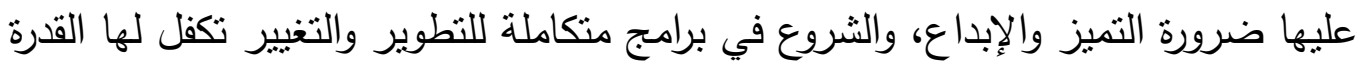

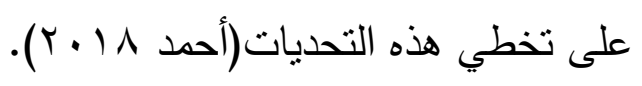

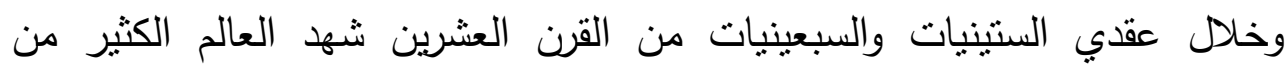

التجديدات التربوية التي اعتمدت بدورها على تطوير المناهج الدراسية وتحسين طرق الترني

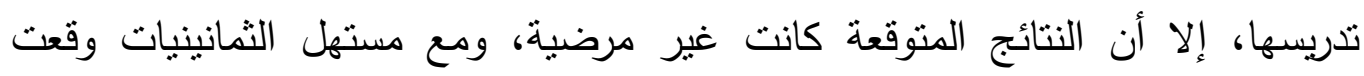

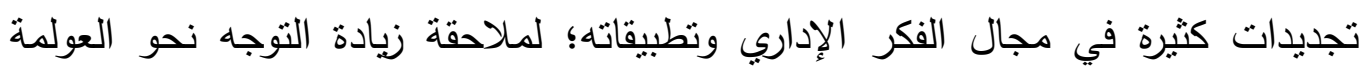
التكنولوجية والاقتصادية والتوجهات الاقتصادية الجديدة والتضخم الدعرفي والتندفق

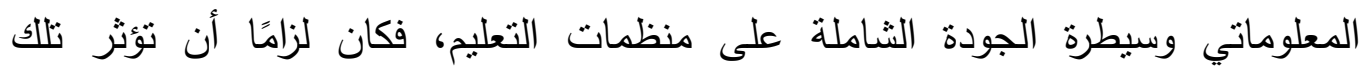

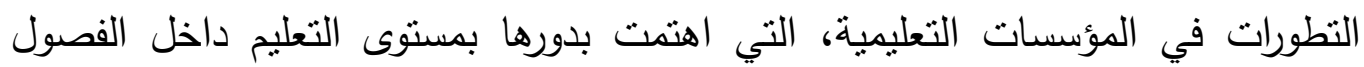

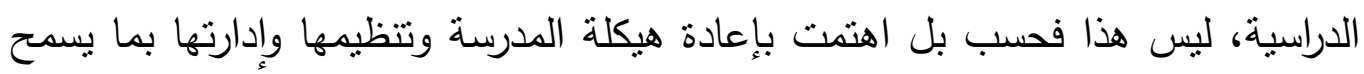

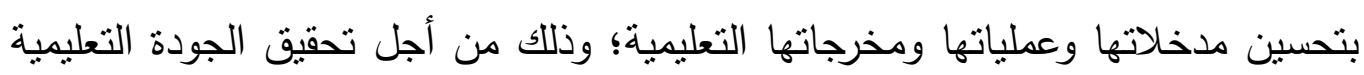

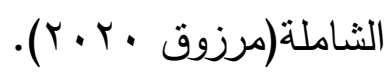

ومن ثم تثكل الإدارة حجر الزاوية في الكثير من المجتمعات الحديثة، كما أنها تعثبر

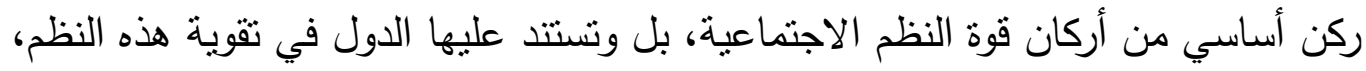

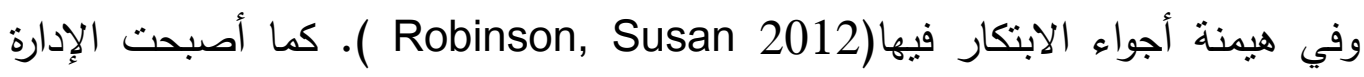

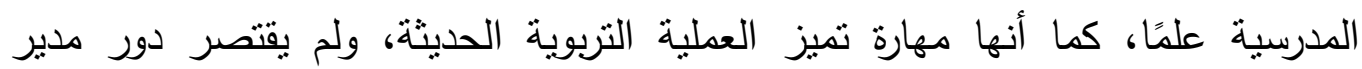
المدرسة والمدراء المساعدين في التعامل الداخلي مع طائفة قليلة من العاملين، بل تجاوز ذللك إلى البيئة الدحيطة (المولى، 9 ( ب ب). 


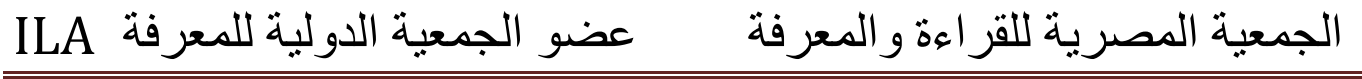

وعلى الرغم من زيادة اهتمام جميع الدول بالتعليم ورصد الأموال الطائلة من ميزانياتها

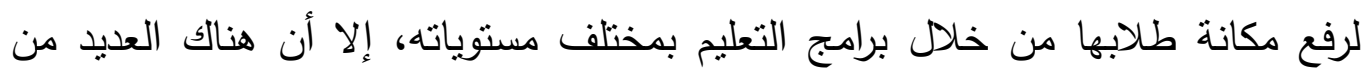
الاتهامات توجه إلى التعليم وخاصة مرحلة التعليم الثانوي والتي تشمل انخفاض جودة التعليم ونوعية المخرجات التعليمية في تلك الدول، وعدم مناسبة مخرجات التعليم مع احتياجات خطط التتمية، ومتطلبات سوق العمل، مع وزيادة تكلفة التعليم في ظل معدلات التضخم المرتفعة وارتفاع نسبة الهدر التربوي في المؤسسات التعليمية (عبدالحميد، $\cdot(r \cdot r \cdot$

ومن التحديات التي تواجه التعليم الثانوي "وهن القيادة الإدارية" حيث يظهر الضعف الإداري في عدم قدرة ترجمة الأهداف المكونة لوظيفة منظومة التعليم إلى سياسات من قِبِل إدارته ممثلة في التظظيم الإداري لها، وعدم استطاعتها تصميم هذه السياسات ووضعها في برامج محددة لحل مشكلات المجتمع، مما أدى إلى ظهور هوة بين المطلوب إنجازه، وبين

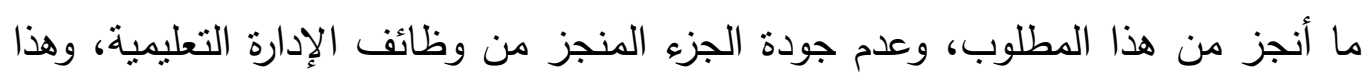
يعني أن الضعف الإداري ينتج عنه في النهاية ضمور في كم وكيف الوظائف التي تقع على كاهل الإدارة التعليمية النهوض بها (المعراج، 9 1 ـ ب). وقد تزايدت الحاجة إلى تطوير التعليم أكثر من أي وقت مضى نظرا للتطورات التكنولوجية والمستجدات العصرية، وتطوير التعليم لن يتم إلا من خلا الاهتمام بالإدارة

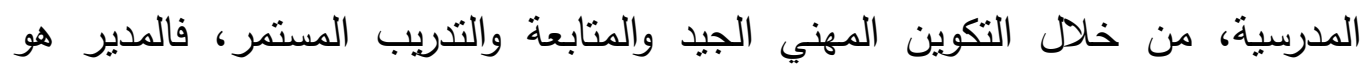

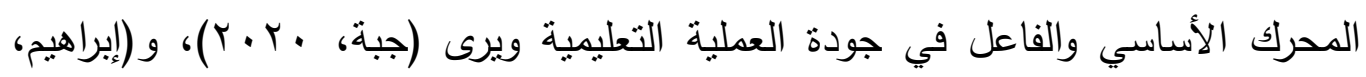

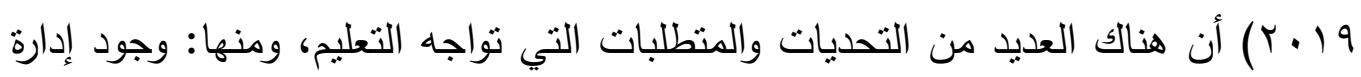
مدرسية حديثة ممثلة في مدير المدرسة الذي ينظر إليه على أنه ممنل للسلطة، وسلوكه القيادي يمثل عنصرا حيويا في أداء مدرسته وتتظيمها فإحساسه بالمسؤولية يهيئه ليكون عضوا بارزا في مجال مهنة التربية والتعليم؛ لذلك عليه أن يكون مبدعا في خططه، ويعمل وبله على تحسين نوعية الحياة المدرسية. 


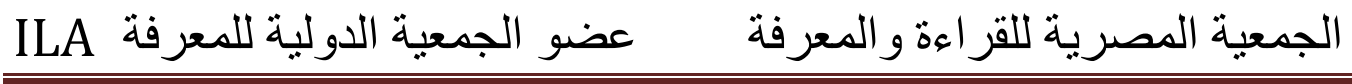

ولقد أضفي على دور مدير الددرسة تطورا عظيمًا مما حوله من مسئول عن تسهيل

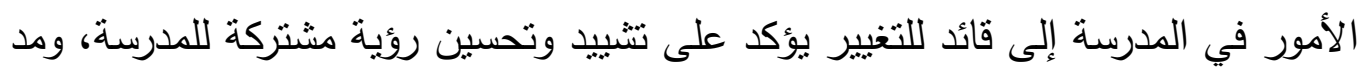

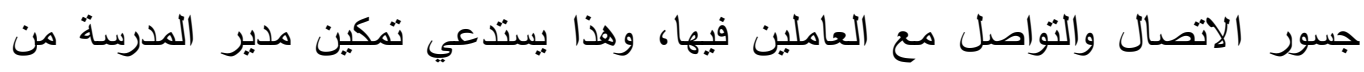

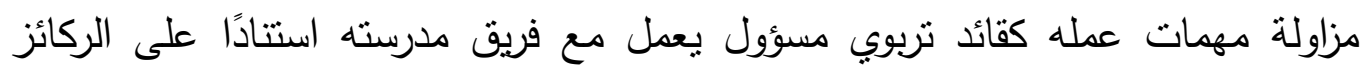
العملية والمهنية والإنسانية، والخصائص القيادية والمهارات، وليس انطلاقا من مفاهيم

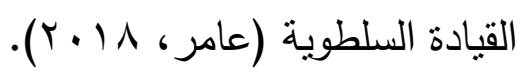

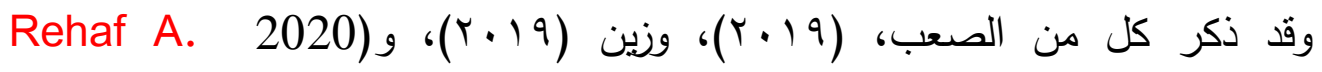
(Madani

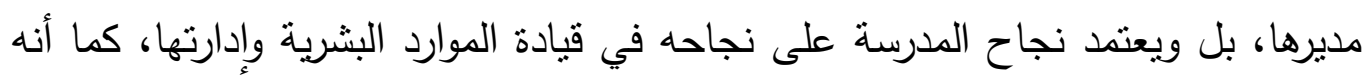

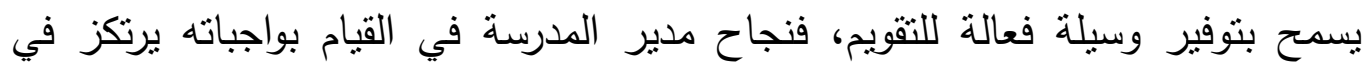

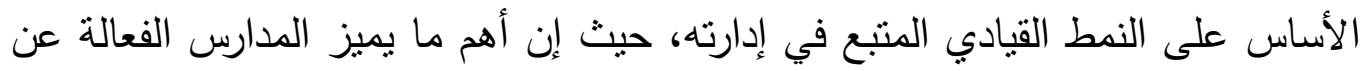

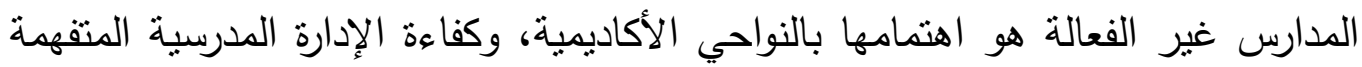
لدورها، والثقة المتبادلة بين العاملين. ومن ثم فان مهمة مدير الدرسة الرئيسة تتمثل في إدارته للمدرسة وبرامجها الدراسية،

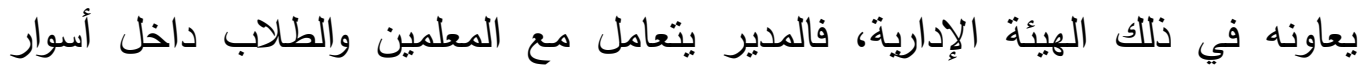

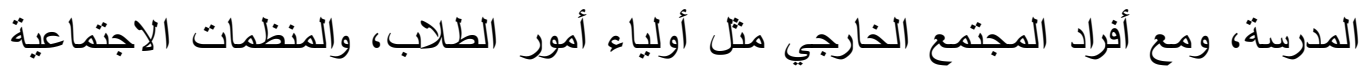

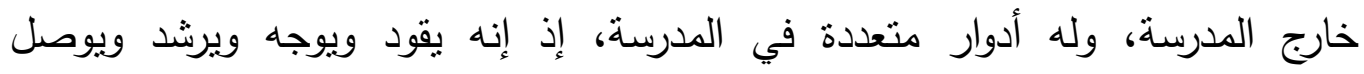
المعلومات، ويصدر التعليمات، ويعتتي بالتاميذ كالأب الناصح، ويهتم بأمر المعلمين الثين

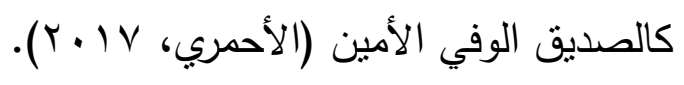

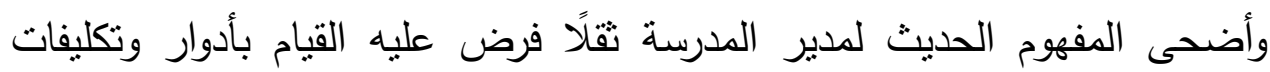
كثيرة لم تكن موجودة سابقًا، فلم تعد مسئولياته مقصورة على الوظائف الإدارية، بل

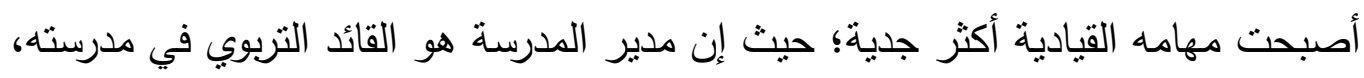

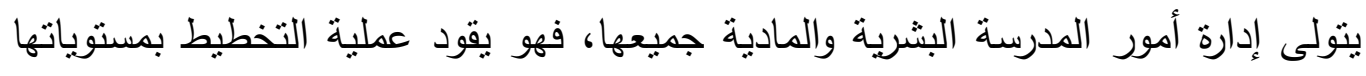




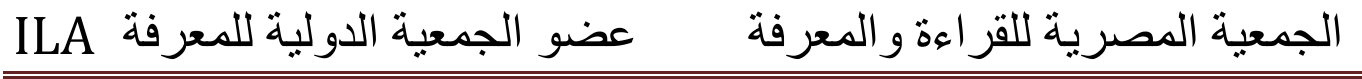

وأثكالها المتعددة، وتطبيق ومتابعة وتقويم الأنشطة التي خطط لها، كما أنه مطالب بتقوية العلاقات الإنسانية بين العاملين وتتجيعهم وتعزيز ميولهم الإيجابية نحو وظيفتهم، والعمل على إثباع حاجات الطلبة والاستجابة لحاجتهم واتجاهاتهم. (الرباط، 7 ( • r). مما سبق يمكن تلخيص دور مدير المدرسة في تحقيق رسالتها من خلا التخطيط والتتفيذ والتقويم والمراجعة لجميع الأنشطة المدرسية، وذلك بتشجيع العاملين وتتميتهم مهنيًا، واستخدام كل الموارد المادية المتوفرة، ونطبيق النظريات التربوية الحديثة، والعمل على تطوير المناهج وتنهيل تدريسها، وتهيئة المناخ المدرسي المناسب لتعلم أمثل للطلاب، ويستوجب كل ذلك أن يكون من نصيب مدير المدرسة الحد الأقصى من الكفايات التي تدفعه لقيادة مدرسته نحو تحقيق أهدافها. ويمكن القول إن تنفيذ الإدارة الإلكترونية وتطبيقها ضرورة ملحة في ظل التغيرات المتتامية والمتلاحقة في شتى المجالات وخاصة في المؤسسات التعليمية؛ حيث إنها المنوط بها تتشئة جيل بمعايير وقدرات تسمح لله بملاحقة هذه التجديدات والتعايش مع متغيرات المستقبل، مما يفرض وجود أداء مؤثز لمديري المدارس، لديه مهارات وقدرات وكفايات تؤهله لقيادة المدرسة، والدفع بها نحو تحقيق أهدافها في ظل هذه المتغيرات.

\section{مشكلة الاراسة:}

اهتمت الكثثر من الدراسات السابقة بطرق تطوير أداء مدراء المدارس عامة، ومديري المدارس الثانوية على وجه الخصوص، ومبررهم في ذلك الأهمية البالغة التي تنالها إدارة المدرسة الثانوية نظرًا لأنها المرحلة التي تليها مباشرة المرحلة الجامعية من حيث تجهيز الطلاب لتحقيق الأداء الأمتل، وانطلاقًا من هذا قصد البحث إلى نتاول أهمية تطوير أداء القيادات المدرسية بالمرحلة الثانوية بإدارة تعليم محافظة ينبع من خلا الإدارة الإلكترونية

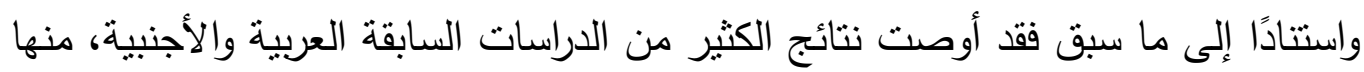

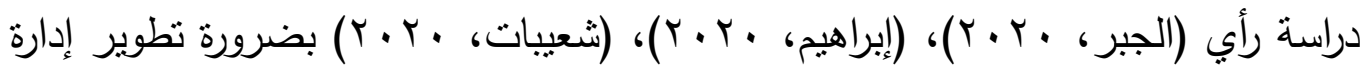
المدارس في ضوء الاتجاهات الحديثة، وفي ضوء تتفيذ الإدارة الإككترونية بالمدارس. 


\section{ILA الجمعية المصرية للقر اءة والمعرفة عضو الجمعية الدولية للمعرفة}

وقد لاحظ الباحث من خلال العمل في الحقل التربوي ضعف أداء القيادات المدرسية بالمرحلة الثانوية وحاجته إلى التطوير من أجل الارتقاء بمستوى الممارسات الإدارية

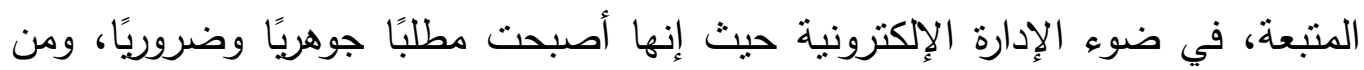
مستلزمات التطوير الإداري بالمدرسة في ضوء المتغيرات والاتجاهات الإدارية الحديثة، وانطلاقًا من هذا سعى الباحث إلى تعرف دور الإدارة الإلكترونية في تطوير أداء القيادات المدرسية بالمرحلة الثانوية بإدارة تعليم محافظة ينبع، وفي ضوء ذللك يمكن صياغة مشكلة البحث في السؤال الرئيس التالي: ما دور الادارة الالكترونية في تطوير اداء القيادات المدرسيه في تعليم محافظة ينبع بالمرحلة الثانوية ؟ ما الاطر النظرية لمدخل الادارة الالكترونية ؟

ما واقع تطبيق الادارة الاككترونية في تطوير اداء القيادات المدرسيه في تعليم

محافظة ينبع بالمرحلة الثانوية؟ أهداف الاراسة: تهاف الدراسة الي التعرف دور الادارة الاكترونية في تطوير اداء القيادات المدرسيه في تعليم محافظة ينبع بالمرحلة الثانوية وذلك من خلال الاهداف الفرعية التالية: 1- التعرف الاطر النظرية لمدخل الادارة الالكترونية. r- الكثف عن واقع تطبيق الادارة الالكترونية في تطوير اداء القيادات المدرسيه في تعليم محافظة ينبع بالمرحلة الثانوية.

\section{أهمية الدراسةة: - مانة}

قد تفيد الدراسة صناع القرار بوزارة التربية والتعليم في ضرورة مراعاة أهم العوامل التي تساعد في تطوير أداء القيادات المدرسية في ضوء الإدارة الإككترونية. 


\section{الجمعية المصرية للقر اءة والمعرفة عضو الجمعية الدولية للمعرفة}

قد تقيد الدراسة القيادات المدرسية أنفسه، حيث تسلط الضوء على أهم العوامل . المدرسية الفعالة في تطوير أدائهم المهني بهدف الوصول بهم إلى السمو والتقدم. قد تساعد الدراسة في تقديم مقترحات تسهم في زيادة فاعلية أداء القيادات المدرسية.

قد تقوي الدراسات التي تتاولت في هذا المجال الأمر الذي يحفز الباحثين على القيام ببحوث أكثر عمقًا أي أنها تفبد الطلاب الباحثين في مجال الدراسات العليا بالجامعات والمؤسسات التعليمية. مصطلحات الدراسة: مفهوم التطوير:

يعرف التطوير بأنه "إدخال كل جديد، أو تبديل في الأفكار أو السياسات أو الأساليب،

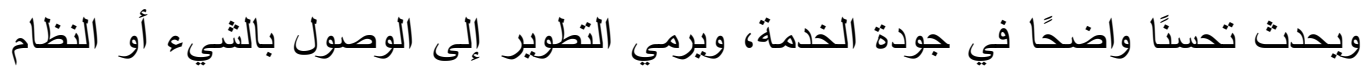

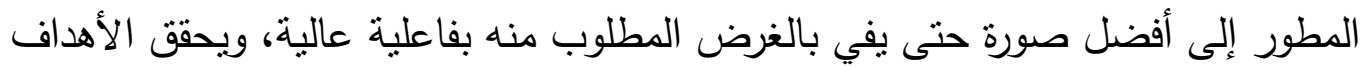
المرجوة على الوجه الأكمل (هنطش، 9 1 • ب). ويعرف التطوير إجرائيا بأنه: "عملية تتمية مهارات الإداريين ومعلوماتهم مما يسهم في هي تحسين أدائهم في العمل، ورفع مستوى كفايتهم في التصدي للمشاكل الإدارية". مفهوم الأداء: يعرف الأداء بأنه "الممارسات والمهام المتوقع من مدير المدرسة أدائها من خلاد إدارته للمدرسة سواء كانت في الناحية الإدارية أو الفنية أو الاجتماعية في ظل الإنهاء الإدارة

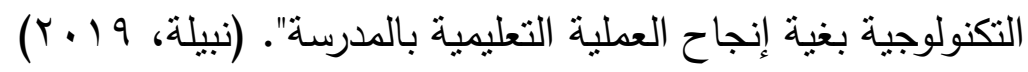
ويعرف تطوير الأداء إجرائيًا في هذه الدراسة: على أنه تتمية معلومات مديري المدارس بله الثانوية واتجاهاتهم الحديثة المرتبطة باستخدام الإدارة الإلكترونية من أجل تمكنهم من أداء 


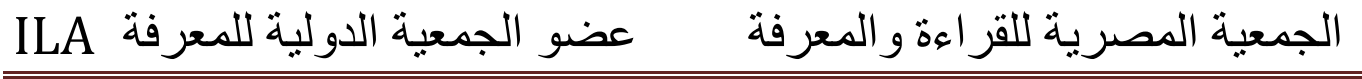

مهامهم بكفاءة وفعالية في شتى نواحي العملية الإدارية مما يظهر ذللك إيجابًا على مستوى تطوير الأداء لديهم وعلى العملية التعليمية بالمدارس.

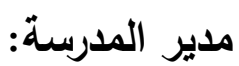

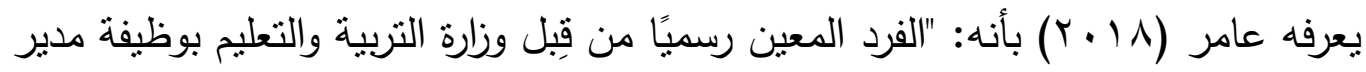
مدرسة ليكون مسئولا عن جميع جوانب العمل في مدرسته لتحقيق بيئة نعليمية فضلى، والعمل على تدبير الموارد والظروف لتحقيق الأهداف المرجوة". ويعرف مدير المدارس الثانوية إجرائيًا في هذه الدراسة بأنهم:" المدراء والمدراء المساعدون القائمون على رأس العمل، والمنوط إليهم تحقيق الأهداف التعليمية، وتطوير مخرجات العملية التعليمية بالمدارس الثانوية الحكومية".

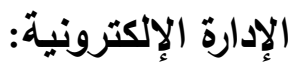

وتعرف كذلك بأنها التنفيذ الفعال للتقنيات المرتكزة على الويب في النظم المقترنة بالموارد البشرية والذي يشترك مع بعض التغييرات التنظيمية الأخرى في توفير إمكانية الولوج إلى بـى بهري المعلومات الخاصة بالموارد البشرية على أوسع نطاق، وكذللك توفير فرص كثيرة لإدارة

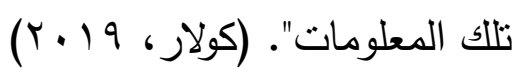
وتعرف الإدارة الإلكترونية إجرائيًا في هذه الدراسة على أنها: منظومة العمل المتكامل الذي يعتمد على استخدام الحاسب الآلي والوسائل التكنولوجية الحديثة ومدى معرفتها وتنفيذها من قبل الإدارة المدرسية بالمدارس الثانوية الحكومية ويظهر ذلك من الدرجات التي سوف تحصل عليها عينة الدراسة من خلال استجاباتهم على الاستبانة. الإطار النظري للاراسة:

تمهيد:

يعد الإبداع الإداري نتيجة ملحة لأسس علمية وقواعد متبعة وليس نتاج تخمين أو

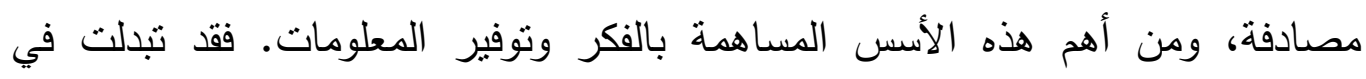
السنوات الخمس عشر الأخيرة العديد من المصطلحات التي تضبط عمل المديرين، فلم 


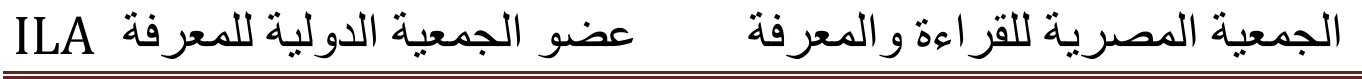

تصبح المشكلة في الإدارة الكلاسيكية المتضمنة في إدارة الأعضاء أو الماليات أو الأعمال الإدارية الأخرى، وانما تمثلت المشكلة التي تتحدى المديرين هي إدارة التغيير المتواصل الذي يتم داخل المنظمة مع اكتسابها الخبرات منزايدة في ظل الكم الهائل من المتغيرات الخارجية المستمرة في بيئة العمل المحيطة بها، وقد أصبح الاتكاء على ثقنية المعلومات والاتصالات أحد الأركان المهمة التي نتبعث منها الإدارة الحديثة. وقد هيمنت ثورة المعلومات والاتصالات على إدارة التغيير بشكل قاطع، وأصبح متاحًا الآن الاستفادة من المعلومات المتوفرة من أجل تحقيق أهداف المؤسسة. (الخولي، 9 ( • ب).

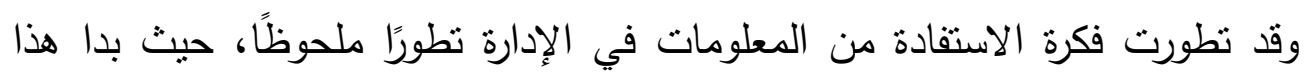

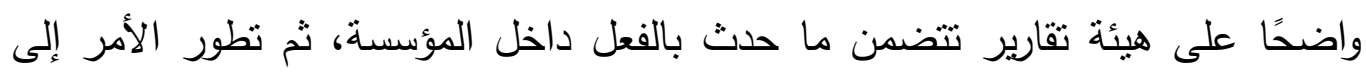
تحليل تلك التقارير للوقوف على أسباب حدوث هذه المتغيرات "لماذا حدث". وانتقلت التقنيات بعملية الاستفادة من المعلومات إلى مرحلة التوقع أي "ماذا سيحدث"، ثم تطورت إلى مرحلة الرؤية الثاملة للمعلومات والتأثنرات المختلفة للقرارات، ثم انتقلت إلى المرحلة الأكثر تقدمًا وهي توظيف المعلومات من أجل تحقيق الأهداف أو ماذا نريد أن يحدث

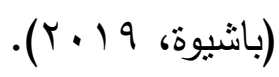

ويعد تطبيق الإدارة الإككترونية هدفًا متميزًا؛ للنهوض بالأداء في المؤسسة التعليمية حيث يعتبر وسيلة لزيادة فعالية الموارد البشرية، وتجويد وتطوير أدائها، وتقليل الأعباء الإدارية عنها. كما أن الإدارة الإلكترونية تعمل على تحسين جودة أداء العمل بالمؤسسات التعليمية عن طريق استخدام وسائل إلكترونية حديثة تتميز بالكفاءة والفعالية والسرعة علاوة على قدرتها على مجابهة كل مشكلات الإدارة التقليدية، والإجهاز عليها. ( Alan

.(B. Albarran 2016

وتعد الإدارة الإلكترونية العمود الفقري لحياة المجتمعات المدنية الحديثة التي كانت طوال حياتها اليومية تواجه مشكلات خانقة في ظل إداراتها التقليدية حتى تمكنت من الخطو خطوات ظاهرة على سبيل تخطي هذه المشكلات بفضل التقنية، بينما لا تزال 


\section{ILA الجمعية المصرية للقر اءة والمعرفة عضو الجمعية الدولية للمعرفة}

مجتمعات أخرى تحبو في أول الطريق الذي يتبارى الأخرون في خطواته النهائية، وينظر إلى الإدارة الإلكترونية على أنها بديل عصري يلاحق التطور الذي أصاب حياة الإنسان

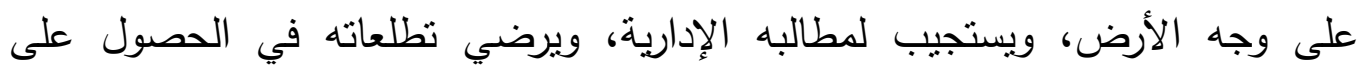
مهارات أعلى وأسهل في إدارة أمور حياته وتفاصيله. إن تعميم ممارسات التقنية في الإدارة ليس شكلًا عصريًا للحياة نسعي لمحاكته، بقدر ما هو حاجة ملحة لمجتمعنا، وحافزًا لتلك الإدارات لتخطي واقعها، والتحرك إلى الآفاق العالمية الواسعة بوتيرة سريعة ومساهمة رحبة (Marutha\& Ngulube 2012). أهمية نظام الإدارة الإلكترونية لمدير المدرسة:

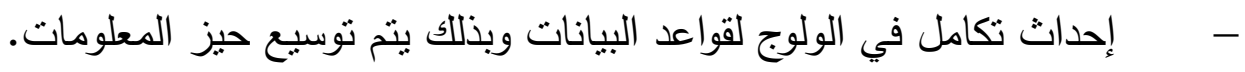
- - م رفع إمكانية وصول الأفراد إلى قواعد البيانات من خلال نموذج البوابات الإلكترونية.

\section{- - - - إدارة المعلومات الثخصية وتقديم الخدمات الجوهرية.} - - ميادة الأفراد بفاعلية أكبر، منل: عمليات التوظيف، وتسجيل الوقت والحضور

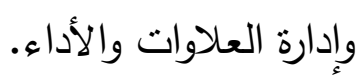
- - - تيسير التعاون والتذريب والتفاعل والمشاركة ونشر المعلومات. - - - التواصل مع العاملين، وتتجيعه، وإدارة الإيجابيات الوظيفية، والمكافأت، وتجويد الخدمة المقدمة لهم

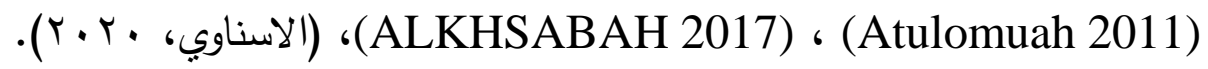
أهداف الإدارة الإلكترونية لمدير المدرسة: توضح (ياسين، 9 ( • ب) أن هناك أهدافًا كثيرة تحاول الإدارة الإلكترونية تحقيقها، منها: - - تعاضد أقسام التظظيم وتوحيدها كنظام متكامل من خلال تكنولوجيا المعلومات. - - مطوير عمليات الإدارة وتقوية فعاليتها في خدمة الأهداف المؤسسية. 


\section{ILA الجمعية المصرية للقر اءة والمعرفة عضو الجمعية الدولية للمعرفة}

\section{- - - - مقديم آليات فعالة ومحفزة لاتخاذ القرارات.}

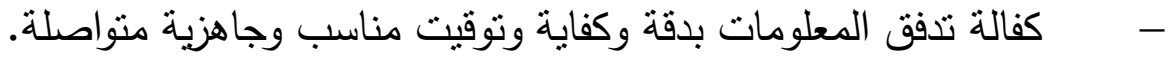
- - مقليل تكلفة التشغيل وتجويد مستمر لنسب الإنتاج.

- - - توفير البيئة والمناخ التنظيمي المناسب للبحث والتطوير الإداري الثامل

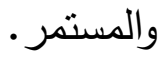

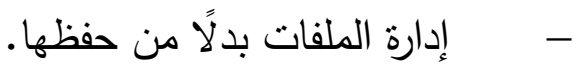

- - عرض المحتويات بدلًا من القراءة.

- - - مالبريد الالكتروني بدلًا من الصادر والوارد.

- - الخطوات التنفيذية بدلًا من محاضر الاجتماعات.

- - - الاتجازات وحل المشكلات بدلًا من المتابعة.

- - - زيادة مستوى الأداء، وتقليل الإجراءات الإدارية.

- - يادة دقة البيانات، فالوثوق بصحة البيانات المتبادلة التي اعبد استخدامها ستعلو ويتلاثى القلق من عدم صحة المعلومات أو الأخطاء الناتجة عن الإدخال اليدوي.

مميزات الإدارة الإلكترونية لمدير المدرسة:

من أهم المزايا والإيجابيات التي يجنيها تطبيق الإدارة الإلكترونية المدرسية داخل المؤسسات التعليمية الآتي: (Panigrahi, 2018) - - ميادة ومتابعة الإدارات المختلفة للمؤسسة وكأنها وحدة مركزية.

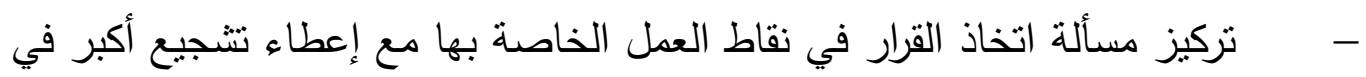
ملاحظتها. - - تجميع البيانات من مواردها الأصلية بشكل موحد. - - - تقليل سلبيات اتخاذ القرار عن طريق إتاحة البيانات وربطها. 


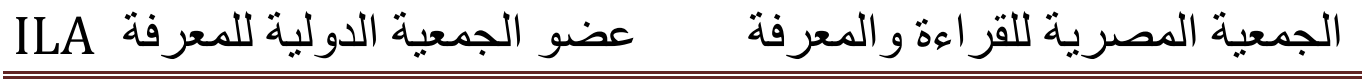

- - - مليص نواحي الصرف في مراقبة عمليات الإدارة المختلفة. - - - استخدام تكنولوجيا المعلومات من أجل دعم ونتييد ثقافة مؤسسية إيجابية لدى جميع العاملين. - - إتاحة البيانات والمعلومات للمستقيدين بصورة سريعة. - - - مالتعلم المستمر وبناء المعرفة. - - - ميادة التماسك بين العاملين والإدارة العليا ومراقبة وإدارة جميع الموارد. أسباب التحول نحو الإدارة الإلكترونية بالمؤسسات التعليمية: إن التوجه نحو الإدارة الإلكترونية ليس نوعًا من الترف، وإنما ضرورة حتمية توجبها

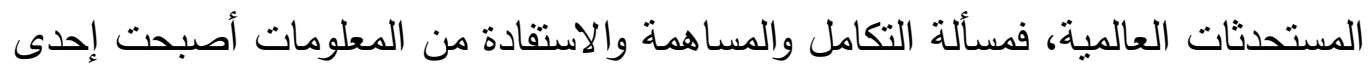
مرتكزات تقدم أي منظمة، وقد أوجب التقدم العلمي والتكنولوجي والمطالبة الملحة بزيادة

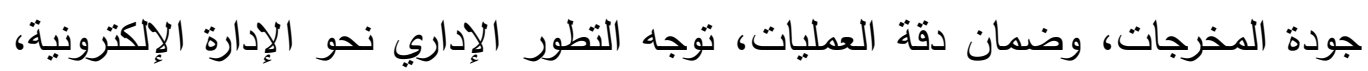
ويشكل عنصر الوقت أحد أهم مجالات التباري بين المنظمات، فلم يعد من المعقول الآن تأجيل تتفيذ العمليات بحجة التحسين والتجويد وذلك لاقتران الفرص المتاحة أمام المنظمات

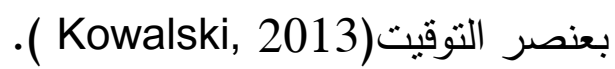

ومن التطورات التي ساهمت في الاتجاه نحو الإدارة الإكترونية، ما يلي: يلي .(al 2016)

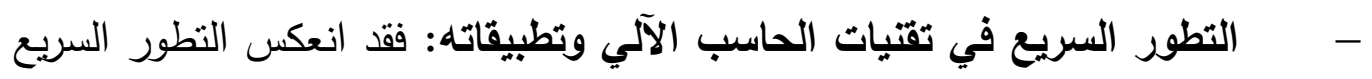
في تقنية الحاسب الآلي على نظريات الإدارة، حيث أصبحت الآلات تتخذ كثيرًا من القرارات المبرمجة محل الإنسان. - - - التقلم السريع في الاتصالات والإنترنت: أدى هذا التقدم إلى تغييرات ملموسة في الإدارة، فالاتصالات الإككترونية أصبحت نوفر للإدارة كل ما يعوزها من معلومات سواء 


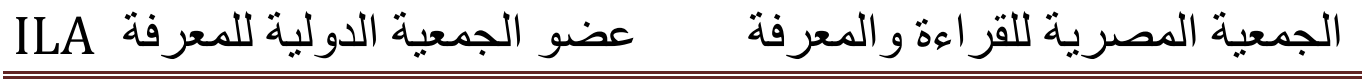

من داخل المؤسسة التعليمية أو خارجها بسرعة ودقة فائقة وبتكاليف زهيدة، مما أدى إلى السرعة في التوجه إلى الإدارة من خلال شاشة الحاسب الآلي وليس الإدارة التقليدية. - - - مالعولمة: لقد ساهمت العولمة في دفع المؤسسات الحكومية وغير الحكومية الخاصة إلى محاولة الانتفاع من التقنيات الحديثة في مجالات الحاسب الآلي والإنترنت والاتصالات من أجل تحسين الجودة ورفع الإنتاج وتقليل التكلفة، وهو ما هيأ لقيام الإدارة الإلكترونية لتحقيق الذات في هذا السباق العالمي سريع الخطى. - - - مثلة الموارد والاتجاه نحو الخصخصة: فقد أدى ازدياد قلة موارد المنظمات الحكومية لبعض الدول عاما بعد عام إلى التوجه نحو خصخصة معظم المؤسسات الخدمية، والتحول نحو تطبيق الإدارة الإككترونية، حتى يتسنى لتلك المؤسسات التعليمية أو الدول ادخار جزء كبير من رسوم أداء الخدمة للمواطنين. - - م انتشار الثقافة الإكترونية: يتميز هذا العصر بشيوع وسائل التعليم عن بعد ووسائل الإعلام والقنوات الفضائية الإعلامية ومقاهي الإنترنت، فأصبح من السهولة بمكان التعامل مع التقنية الرقمية. فلم يعد الأمر يستوجب الحصول على شهادة جامعية متخصصة في الحاسب الآلي للتعامل مع تلك التقنية. - - الاستجابة والتلائم مع متطلبات البيئة المحيطة: إن انتشار وتتفيذ مصطلح وطرق الإدارة الإلكترونية في كثير من المؤسسات التعليمية والمجتمعات يفرض على كل دولة اللحاق بركب التطور تلاشيًا لاحتمالات الانعزال والتخلف عن ملاحقة عصر السرعة والمعلوماتية، فلا يمكن لأي مجتمع إنساني حديث أن يعيش كنظام مغلق. مراحل التحول إلى الإدارة الإلكترونية بالمؤسسة التعليمية: يحتاج التوجه نحو الإدارة الإكترونية إلى العديد من الخطوات كي تحدث العملية بشكل

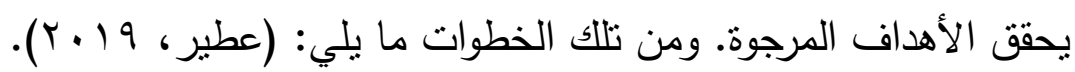




\section{الجمعية المصرية للقر اعة و المعرفة عضو الجمعية الدولية للمعرفة}

- - متاعة وتثجيع الإدارة العليا: يجب على المسئولين بالمؤسسة التعليمية امتلاكهم القناعة الكاملة والروئة الثاملة لتغيير جميع المعاملات الورقية إلى إلكترونية كي يقدما التشجيع الكامل والإمكانيات الضرورية للتحول إلى الإدارة الإكترونية. - - - تدريب وتأهيل العاملين: العامل هو العنصر الجوهري للتوجه نحو الإدارة الإلكترونية، لذا يجب تدريب وتأهيل العاملين حتى يؤدوا الأعمال خلال الوسائل الإلكترونية المتوفرة، وهذا يتطلب إقامة دورات تدريبية للموظفين، أو تأهيلهم على رأس العمل.

- - موثيق وتطوير إجراءات العمل: لكل مؤسسة مجموعة من العمليات الإدارية أو ما يسمى بإجراءات العمل، فبعض تللك الإجراءات ليس مكتوبًا على ورق، أو أن بعضها مكتوب منذ سنوات بعيدة ولم يصبها أب تطوير؛ لذا لابد من توثيق جميع الإجراءات وتطوير القديم منها كي تتماشى مع حجم العمل، ويتم ذلك من خلال تحديد الهدف لكل عملية إدارية تتحكم في سير العمل، وتطبيقها بالوسائل النظامية. - - - إتاحة البنية التحتية للإدارة الإلكترونية: يقصد بالبنية التحتية الجزء الملموس في الإدارة الإككترونية، من صيانة أجهزة الحاسب الآلي، وربط الثبكات الحاسوبية والأجهزة المرنبطة معها، وتوفير وسائل الاتصال الحديثة. - - - - البدء بتوثيق المعاملات الورقية القديمة إلكترونيًا: يجب حفظ المعاملات الورقية القديمة والمخزنة في الملفات الورقية إلكترونيًا بواسطة الماسحات الضوئية، وتصنيفها لتيسير الرجوع إليها. - - - البدء ببرمجة المعاملات الأكثر انتشارا: البدء بالمعاملات الورقية الأكثر انتشارا في الأقسام كلها وبرمجتها إلى معاملات إلكترونية لتقليص الخسائر في الورق المستخدم. 


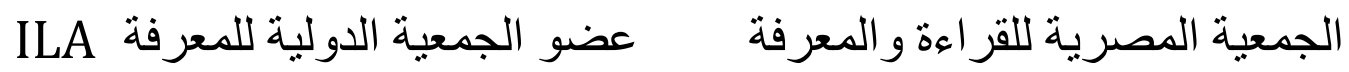

\section{خطوات تطبيق الإدارة الإلكترونية بالمؤسسات التطليمية:}

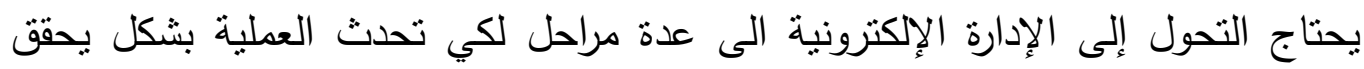

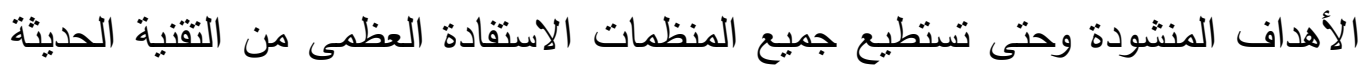

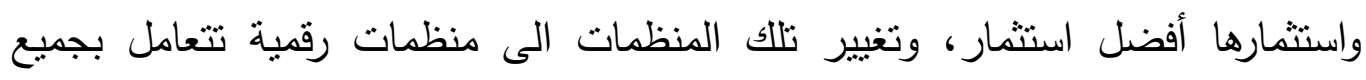

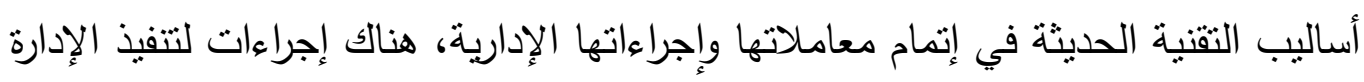

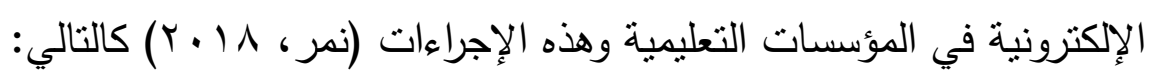

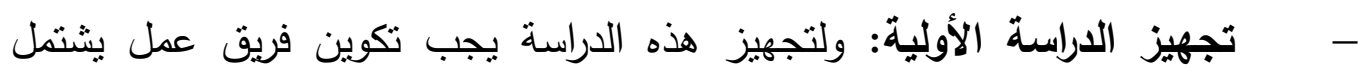
بعضويته متخصصين في الإدارة والمعلومانية؛ بهدف الوقوف على حال الإدارة من تقنيات

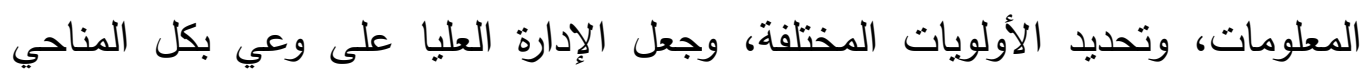
المالية والفنية والبشرية. - - - إعداد خطة التنفيذ: عند إقرار توصية الفريق من قبل الإدارة العليا في تتفيذ

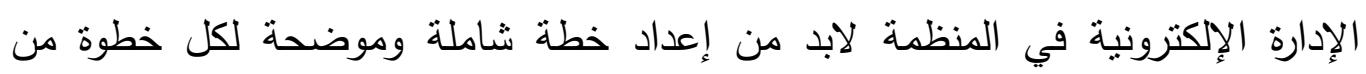
خطوات التطبيق. - - مديد المصادر: وهي المصادر التي تساند الخطة بشكل دقيق ومحدد، وتشتمل

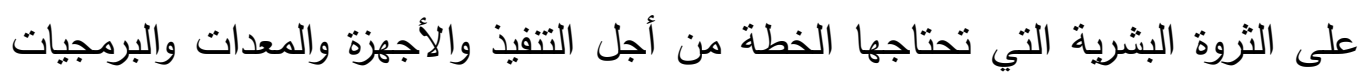

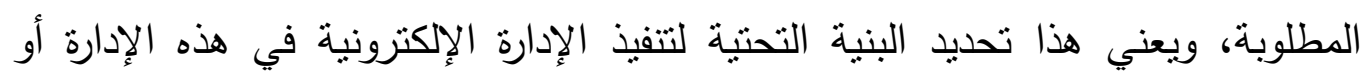

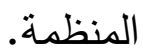
- - تحديد المسؤولية: يجب تحديد الجهات التي سوف تقوم بتنفيذ الخطة وتمويلها بشكل دقيق ضمن الوقت المحدد في الخطة والتكلفة المحدة لها. 


\section{الجمعية المصرية للقر اءة و المعرفة عضو الجمعية الدولية للمعرفة}

- - متابعة التقدم التقتي: لابد من متابعة كل مستجدات المجال التقني من اتصالات وأجهزة وبرمجيات وغيرها من العناصر التي لها علاقة بهذا المجال وذلك نظرا للتطور المتنامي في مجال تقنيات المعلومات الإدارية.

\section{وظائف الإدارة الإكترونية بالمؤسسات التعليمية:}

تبدلت وظائف الإدارة المدرسية وتعددت مجالاتها في الوقت الراهن، فلم تعد مجرد عملية تقليدية هدفها تسهيل العمل في المدرسة طبقًا لأسس وإرشادات موجهة من السلطات التعليمية العليا، كالحفاظ على المنظومة المدرسية، والحرص على مراقبة غياب الطلاب وحضورهم، وفهمه للمواد الدراسية، والحفاظ على الأبنية المدرسية وبنيتها التحتية وغيرها،

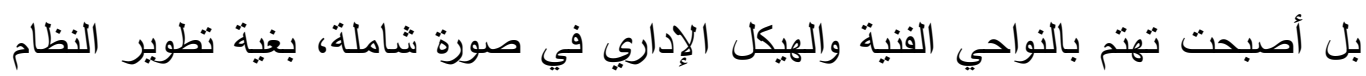

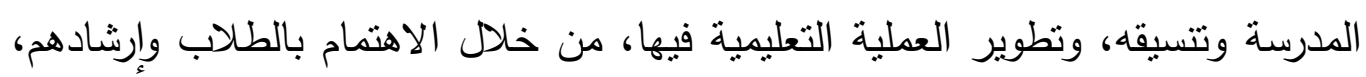
وتجويد أداء المعلمين وتتميتهم مهنيًا، وتحسين تطبيق المناهج الدراسية، وتطوير الاستراتيجيات التربوية والأنشطة والبرامج المدرسية، وتقوية علاقة المدرسة بالمجتمع المحلي، وتعد الإدارة الإككترونية أحد التوجهات الرئيسة والحديثة في إنجاز مهام المدرسة ولتهن بصورة أسرع وأدق من السابق في عصر المعرفة والتطور السربع المنلاحق، وهناك الكثير من وظائف الإدارة الإلكترونية نحتاج إليها في المدارس الثانوية، من هذه الوظائف

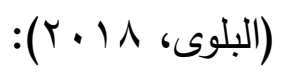

أولًا - استخدام الإدارة الإلكترونية في التخطيط المدرسي: - - - مإتاحة كم كبير من المعلومات المختلفة التي تتكل ركن الزاوية في عملية التخطيط.

- - مهولة الولوج للمعلومات في الزمان والمكان المناسبين.

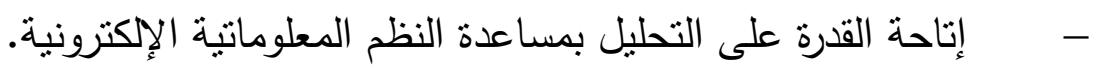
- - القدرة على تعرف شتى الإمكانات المتوفرة للمؤسسة التعليمية. 


\section{الجمعية المصرية للقر اءة والمعرفة عضو الجمعية الدولية للمعرفة}

القدرة على إتاحة معلومات مهمة من كل عناصر الخدمة والبيئة الخارجية بمرونة

كافية.

- - زيادة تدفق المعلومات للمؤسسة التعليمية مما يسمح بدقة أكثر في عملية التخطيط. (العجمي، IV ( IV).

- - زيادة قدرة مدراء المدارس الثانوية على تشخيص المشكلات نتيجة القدرة على جمع المعلومات.

- مساندة قدرة مدراء المدارس الثانوية على تحديد البدائل المختلفة وتقويم كل بديل. - - - ميادة قدرة مدراء المدارس على تقلييد الواقع أو المحاكاة والنماذج الواقعية عن طريق استخدام نظم المعلومات الإكترونية. - - - - القدرة على تفعيل ومساندة القرارات باللجوء إلى نظم معلوماتية موجهة. - - - القدرة على مجاراة قصر الوقت المتاح لمتخذي القرار في عصر الثورة المعلوماتية

.(Rawahneh, 2013)

ثانيًا - استخدام الإدارة الإلكترونية في التنظيم: يعد التتظيم من المهام الإدارية الضرورية، فالتتظيم هو وظيفة من وظائف المسير تشنمل على تحديد الأنشطة المطلوب إتمامها لتحقيق الأهداف، وتخصيص الأفراد الذين سيقومون هون وطن بتطبيق هذه الأنشطة، بحيث يتم تكليف الشخص بنشاط محدد يتماشى مع قدراته و منطلبات هذا النشاط، وتحديد مراكز السلطة والمسؤولية، وطرق المتابعة والتتسيق بين الأنشطة، علاوة على تشبيد الهيكل التنظيمي الذي يبين من الذي يقوم بماذا، ومن المسؤول عن ماذا ..إلخ، والنتائج المرجو تحقيقها. وقد ذكر( ) عددًا من الأمثلة لأنشطة إدارية يمكن استخدام الحاسب الآلي في إنجازها إلى اللجوء لعملية التنظيم نذكر منها ما يلي: 


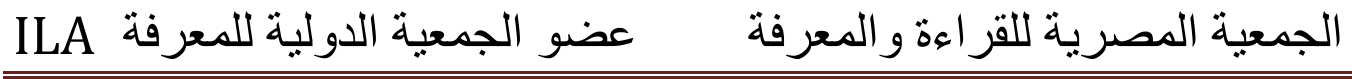

- - - تجهيز الدليل التظظيمي للمدارس، ومن ثم حفظه على الحاسب، حيث يتضمن وصفًا للمهام الأساسية، ويرجع إليه عند تغيير اختصاصات بعض الوظائف. - - مالقدرة على متابعة مهارات الطلاب، ومن ثم إبراز النواحي الإيجابية والسلبية لديهم، مما يسهم في وضع الخطط العلاجية أو الإجرائية لهم. - مراقبة نسبة تخرج الطلاب أول قبول طلاب جدد معدل الدوران (حيث يتم التتبؤ باحتمالات التخرج)، ومن ثم التجهيز لأعداد الطلاب الجدد.

- - - ميسر وسهولة عملية الاتصالات الداخلية أو الخارجية بين المدارس من خلص "البريد الإككتروني "مما يقلل عبء تجهيز المراسلات الداخلية ومتابعة عملية استلامها. ثالثًاً- استخدام الإدارة الإلكترونية في اتخاذ القرار: تعد عملية اتخاذ القرار عملية أساسية وذات أهمية بالغة بالنسبة للمؤسسة التربوية وخاصة الإدادية

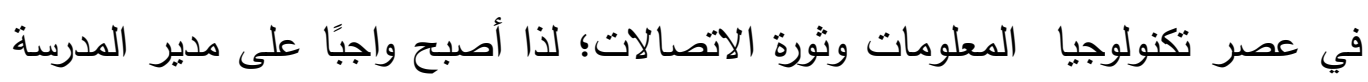
الثانوية استخدام الحاسب الآلي في توجيه عملية اتخاذ القرارات الإدارية، وما ذلك إلا للإِيجابيات الجمة التي يتصف بها الحاسب الآلي. وقد ذكرت (atrill, peter 2017) تلك الإيجابيات في النقاط التالية: - - - الحصول على المعلومات الضرورية لعملية اتخاذ القرارات في سرعة ودقة. - - محة المعلومات التي يوفرها الحاسب الآلي لصانعي القرار • - - - كفاءة الاتصالات الإدارية بين مختلف مستوياتها. - - - التوفير الكبير في الوقت والجهد، وتلاشي الأخطاء. - تخفيض الاستتاد على الحس في صنع القرارات. - - دعم القدرة على تشخيص المشكلات نتيجة القدرة على تحصيل المعلومات. - - - ميادة القدرة على تحديد البدائل المختلفة، وتقويم كل بديل. 


\section{ILA الجمعية المصرية للقر اعة والمعرفة عضو الجمعية الدولية للمعرفة}

- - - ميادة القدرة على محاكاة الواقع أو التقلييد أو النمذجة الواقعية باستخدام نظم المعلومات الإلكترونية. - - - القدرة على تتشيط ودعم القرارات باللجوء إلى نظم معلومانية موجهة لذلك، كنظم دعم ومساندة القرارات.

- - - القدرة على مجاراة قصر الوقت المتاح لمتخذ القرار في عصر الثورة المعلوماتية. رابعًا - استخدام الإدارة الإلكترونية في القيادة التعليمية: أنها عملية السيطرة على الأفراد باتجاه تحقيق أهداف المؤسسة التعليمية، والمسألة الرئيسة التي يجب الانتباه إليها، هي حاجة المؤسسات التعليمية للقيادة القوية والنظام الإداري

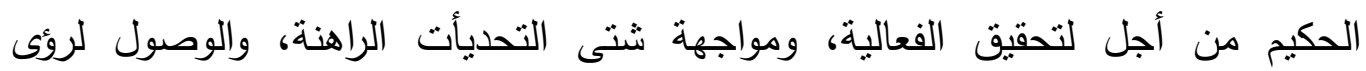
مستقبلية، وإيجاد التركيب التنظيمي الكفء، ومتابعة العمليات اليومية (الثافعى، 9 ( • ب).

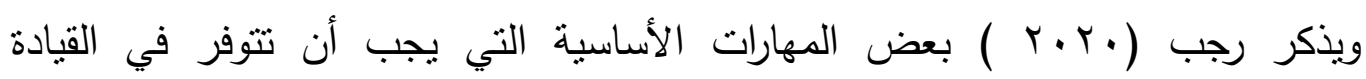

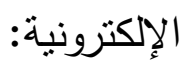

- - مهارات المعارف الإكترونية: مثل تقنية المعلومات في الحاسبات الآلية وشبكات الاتصالات الإكترونية والبرمجيات الخاصة بها والتعامل الكفء معها. - - مهارات الاتصال الفعال مع الآخرين: حيث يتطلب هذا الأمر ضرورة إقامة علاقات عمل جديدة من خلال استخدام كافة أنواع الاتصالات سواء كانت مكتوبة أو شفهية. - مهارات إدارية: وهي تشمل مهارات تشجيع الأفراد الآخرين بالمنظمة نحو العمل الجماعي والتعاون 


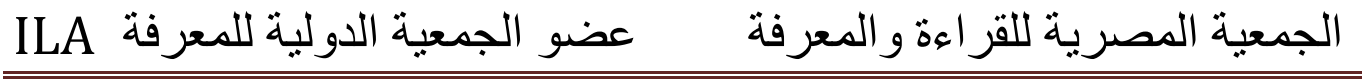

فالقائد الإككتروني مطالب باتخاذ قرارات سريعة وفورية لما هو مطلوب الآن وفي كل مكان مما يجعله في حاجة لتطوير اتجاهات وأسس خاصة الحالات المختلفة رغبة في المسارعة من أجل حل المشكلات.

\section{خامسًا - استخدام الإدارة الإلكترونية في التوجيه:} لما كان التوجيه من أهم أعمال الإدارة فهو بالتالي أهم أدوار مدير المدرسة وبظهر دورهيه الإنها

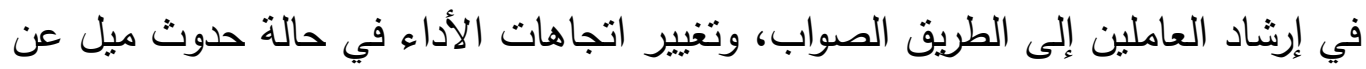
الطريق، وهذا يتطلب الإرشاد الصحيح وإتاحة المعلومات الضرورية عن الأداء الفعلي لجميع العاملين؛ لذا فالتوجيه يرمي إلى تطبيق الأعمال المخطط لها تطبيقًا سليمًا، والوصول إلى الهدف المرجو بأعلى كفاية ممكنة. ويشير (الحيت، 10 • ب) إلى أن التوجيه الإلكتروني للمنظمات الحالية يعتمد على وجود القيادات الإلكترونية والتي تحاول تنشيط دور الأهداف الديناميكية والسعي في تحقيقها، كما يعتمد أيضًا وجود كفاءات لديها القدرة على التعامل بفاعلية إلكترونيًا مع الأفراد الآخرين، والقدرة على تشجيعهم ومساهمتهم في إتمام الأعمال المسنودة إليهر كما يعتمد التتفيذ الفعال للتوجيه الإلكتروني على استخدام شبكات الاتصالات الإلكترونية المنقدمة كشبكة الإنترنت بحيث يتم إتمام وتطبيق جميع عمليات التوجيه من خلالها. وبالتالي فمن الضروري أن تسعى المؤسسات التعليمية جاهدة إلى تجهيز عناصرها البشرية وتدريبهم على استخدام الحاسب الآلي، و المحفزات المادية والمعنوية للفائقين منهم، وتوفير مبدأ التنافس في المؤسسة التعليمية، وانتقاء المؤهلين في مجال تقنية المعلومات عند ولثات

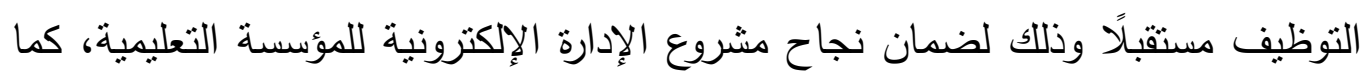

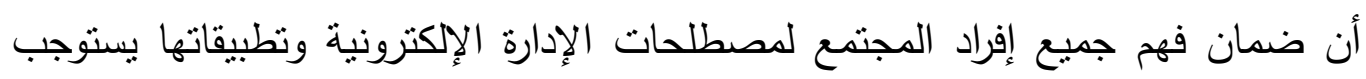

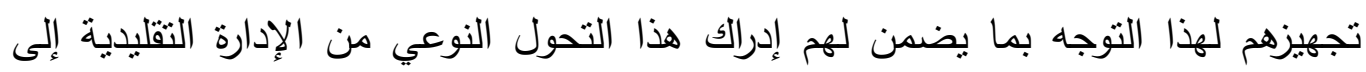
الإدارة الإلكترونية (إسماعيل 7 ( • ب). 


\section{ILA الجمعية المصرية للقر اءة والمعرفة عضو الجمعية الدولية للمعرفة}

\section{سادسًا - استخدام الإدارة الإلكترونية في الرقابة:}

تعد الرقابة من أكثر عناصر العملية الإدارية استتزافًا لوقت الإدارة المدرسية، حيث الإديه

يجب على مدير المدرسة التأكد من وجود منسوبي المدرسة، ومدى الحرص على زمن الحصص الدراسية، وموعد دخول الحصة والخروج منها، وسير العملية التعليمية في المدرسة، ومستويات التلاميذ، وتطبيق الأنشطة وغيرها من الأدوار الإدارية التي تتطلب

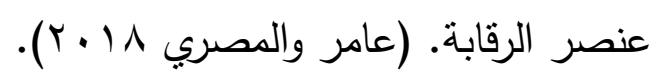

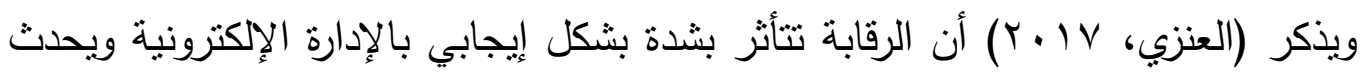
ذلك عن طريق:

- - - سهولة الولوج إلى المعلومات وضبط الدخول عليها. - - - القدرة على الإشراف على العمليات المختلفة، وسير القرارات المتعددة في شتى أنواع المؤسسات التعليمية. - - - مالقدرة على عرض اللوائح والإجراءات الخاصة بالخدمات الحكومية، وأسس تقديمها، وتيسير مطالعتها إلكترونيًا. - - - مإمكانية توضيح المسؤولية بتعرف متخذ القرار، والقدرة على المساعلة عند الوقوع في الأخطاء. - توفير وسائل اتصال منتوعة لتتاقل المعلومات. - - - القدرة على الانتهاء من الخدمات إلكترونيًا خلال شبكة الإنترنت، وذلك بتوفير معلومات متكاملة عن الإجراءات الإدارية واحتياجاتها، مما ييسر عملية الإشراف. - - - القدرة على طرح مشروعات القواعد والأنظمة على المواقع الإلكترونية، مما ييسر إدراكها من مختلف أعضاء الخدمة.

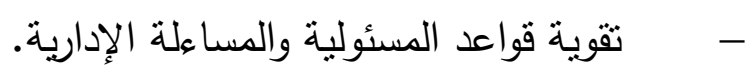




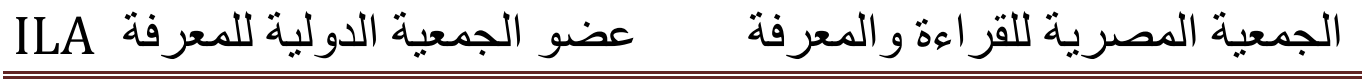

- - - مالعليات والآليات: تقود الإدارة الإلكترونية إلى التبدل في الإجراءات الحكومية والذي يشمل العديد من نأثنرات ثانوية منه. - - - القيام بتغيير نوعي وكمي في التعاملات والخدمات لتشمل أركان وحدود الإدارة الإلكترونية المتتوعة. سابعًا - استخدام الإدارة الإلكترونية في التقويم: التقيم هو الإجراء الذي يتوصل من خلاله إلى المعلومات والأحكام على دراسة معينة لحدث، للتثبت من الوصول للنتائج المرجوة، وهو مصدر أساسي للحكم على فاعلية البرامج والممارسات التي تقدمها منظمات الخدمة الاجتماعية، وعلى الرغم من استتاد التقويم على مجموعة متميزة من المصطلحات، منل: المدخلات والعمليات والمخرجات، إلا إنه يرتكز في الأساس على نقطة واحدة هي: هل العمل فعال أم لا؟ (تمام، 9 ( • ب) وتتكل عملية التقويم عنصرًا مهمًا من عناصر عملية الإدارة؛ حيث إنها تمثل قمة العمليات الإدارية المختلفة التي يحدث فيها تقويم مدى تحقق الأهداف التي اتفق عليها في الخطوات الإدارية السابقة على عملية التقويم. يعتبر التقويم وسيلة لا غاية تساعد مدير المدرسة على الوقوف على حسن سير العملية التعليمية، ومدى تحقيقها لأهدافها، وتوفر تطبيقات الحاسب الآلي المختلفة لإدارة المدرسة إمكانية الإشراف وتقييم الأداء لجميع أعضاء المدرسة من خلا متابعة أدائهم، وإنشاء

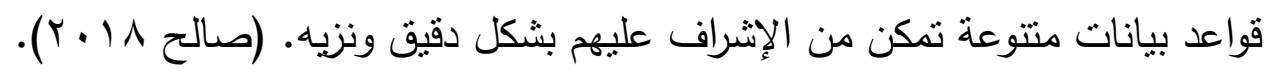
إن انتفاع الإدارة المدرسية بالتكنولوجيا الحديثة يساعد مدير المدرسة على مطالعة التقارير

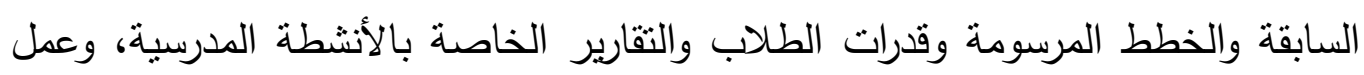

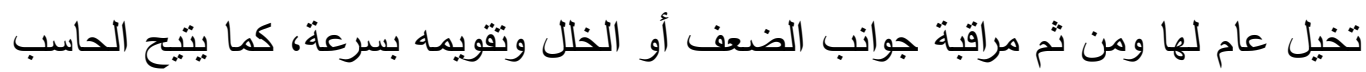
الآلي لإدارة المدرسة رؤية تجارب المدارس الأخرى والاستفادة منها، كذلك يساعد المشرف ونه التربوي رؤية تحضير المعلمين الذين يتابعهم، والدروس النموذجية التي أعدوها كل ذلك رؤي 


\section{الجمعية المصرية للقر اءة والمعرفة عضو الجمعية الدولية للمعرفة}

وهو في مكتبه من خلال شبكة الإنترنت، وإصدار الإرشادات الضرورية لهم (مرسى ، . ( r. Y V

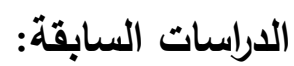

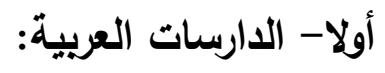

دراسة (الجبر، •.r.r). هدفت الدراسة الحالية إلى التعرف على واقع تطبيق الإدارة

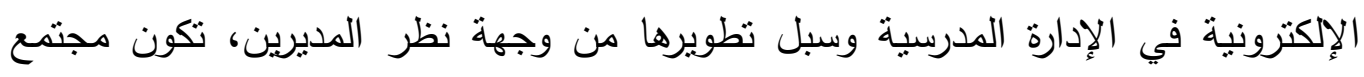
الدارسة من جميع مديري ومديرات الددارس الحكومية الثانوية في لواء الجيزة بالبادية

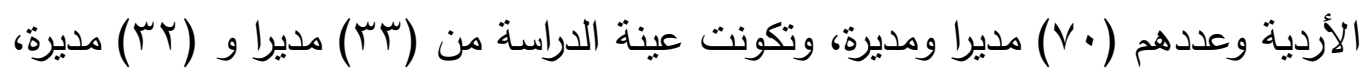

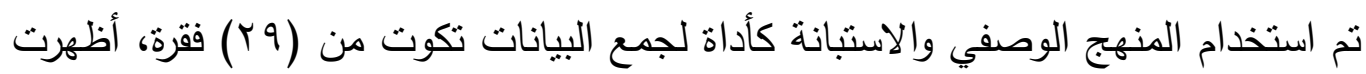

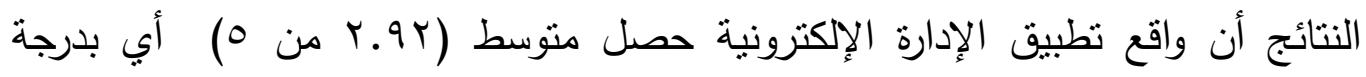

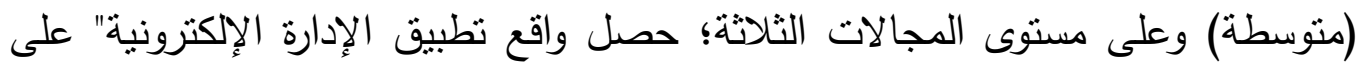

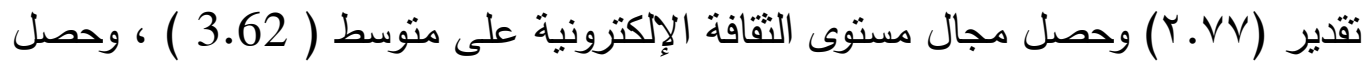
مجال مقترحات تطوير تطبيق الإدارة الإكترونية على متوسط (Y.T.Y)، وجميعها بتقدير

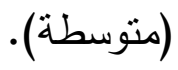

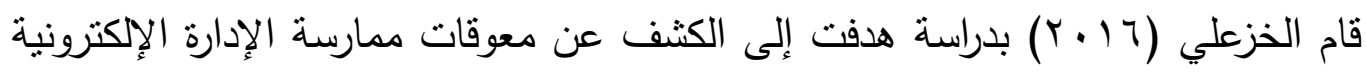

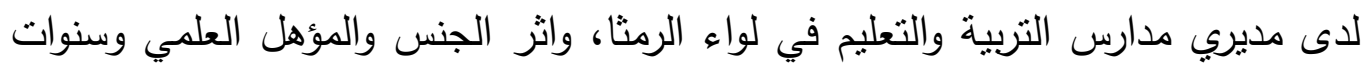

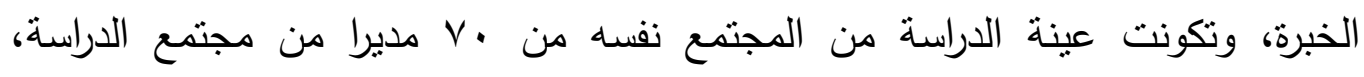

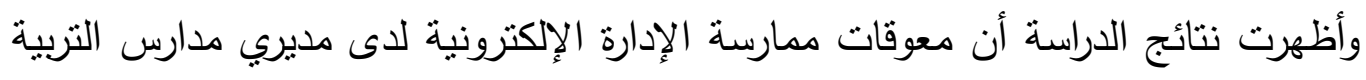
والتعليم في لواء الرمثا جاءت مرتفعة عن جميع المجالات حسب وجهة نظر الديرين،

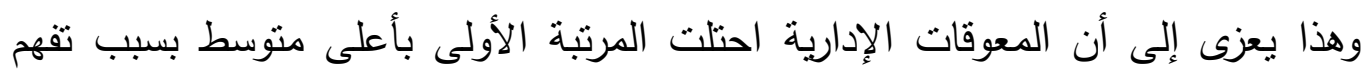

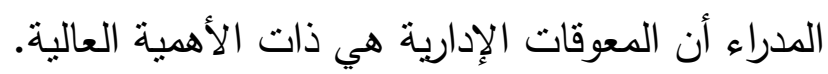

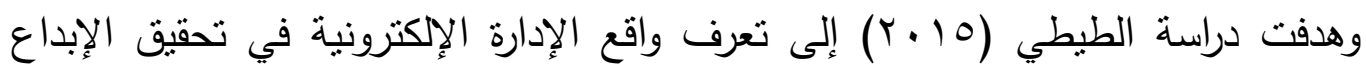

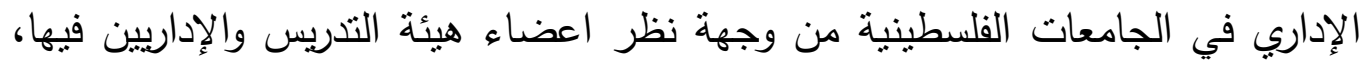




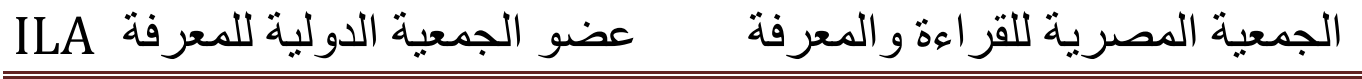

وبلغ عدد أفراد العينة r م أكاديميا وإداريا. و أظهرت نتائج الدراسة وجود فروق جوهرية تبعا لمتغير الجنس عند جامعة القدس والخلسل لصالح الذكور ، ووجود فروق تبعا لمتغير التخصص تبعا لجامعة القدس حيث إن الفروق كانت لصالح اللوم الطبيعية، ووجود فروق تبعا لمتغير الوظيفة الحالية لجامعة القدس حيث إن الفروق كانت لصالح عضو هيئة تدريس على المجال الكلي لواقع الإدارة الإلكترونية في الجامعات الفلسطينية. ثانيا- الدراسات الأجنبية:

دراسة (Oyedemi, 2015) هدفت التعرف إلى وجهات نظر الاداريين نحو استخدام تكنولوجيا المعلومات والاتصالات لإدارة المدرسة الفعالة ولتحقيق أهداف الدراسة استخدم الباحث المنهج الوصفي التحليلي، وتم استخدام الاسنبانة كأداة للاراسة، وأظهرت النتائج وجود اتجاهات ايجابية لدى مديري المدارس الثانوية ونوأيهم تجاه استخدام أدوات تكنولوجيا المعلومات والاتصالات كما اظهرت النتائج وجود نقص واضح في الأجهزة والثبكات في المدرسة.

وهدفت دارسة (Fritz 2015) إلى معرفة العلاقة بين ممارسة القيادة المدرسية للمدارس الحكومية للإدارة الاستراتيجية في مدينة نيس الفرنسية وتطوير أداء المعلمين بهذه

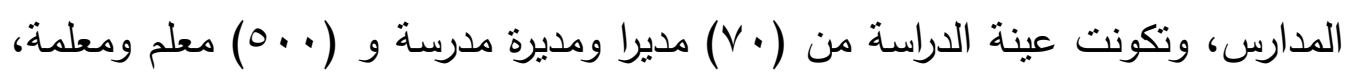
وتم استخدام المنهج الوصفي التحليلي، وتكونت أدوات الدراسة في استبيانين أحدهما لقياس تطبيق القيادة الاستراتيجية والأخر لقياس الأداء الوظيفي للمعلمين، وتوصلت نتائج الدراسة ولته إلى أن ممارسة القيادة الاستراتيجية من قبل قادة المدارس يعد مرتفعا ، وأن مستوى الأداء الوظيفي للمعلمين يعد مرتفعا كذلك، وأثنارت النتائج إلى وجود علاقة ارتباطية ايجابية بين تطبيق القيادة المدرسية للإدارة الاستراتيجية والأداء الوظيفي للمعلمين. تعليق عام على الاراسات السابقة: - معظم الدراسات السابقة استخدمت المنهج الوصفي. - - معظم الدراسات التي تم عرضها استخدم الاستبانة كأداة لجمع البيانات. 


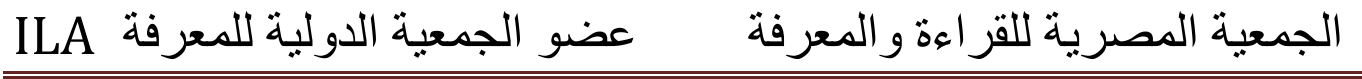

- - - تتاولت الدراسات السابقة دور الإدارة الإلكترونية في تطوير العمل الإداري بالمدارس والجامعات.

\section{أوجه الثبه والاختلاف بين البحث الحالي والدراسات السابقة:}

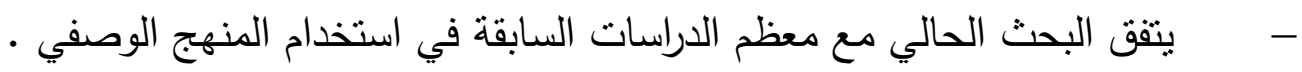
- - - يتفق البحث الحالي مع معظم الدراسات السابقة في استخدام الاستبانة كأداة الجمع البيانات.

- - مختلف البحث الحالي مع الدراسات السابقة في العينة المطبق عليها البحث - - يتفق البحث الحالي مع الدراسات السابقة في محاولة تطوير اداء القيادات المدرسيه الثانوية في ضوء مدخل الإدارة الإلكترونية.

- - متنف البحث الحالي عن الدراسات السابقة في مجتمع البحث وبيئة التطبيق. أوجه الاستفادة من الاراسات السابقة: - - ميمن إجمال جوانب الاستفادة من الدراسات السابقة على النحو التالي: - - - آن البحث الحالي يبرره بعض من توصيات ونتائج الدراسات السابقة. - - - ميستقيد البحث الحالي من الدراسات السابقة في تعرف المعوقات التي تواجه تطبيق مدخل الإدارة الإلكترونية في الإدارة الددرسية بالتعليم الثانوي - - يستقيد البحث الحالي من الدراسات السابقة في توضيح أدبيات وفي بناء أداة الدراسة. - - يستفيد البحث الحالي من الأساليب الإحصائية التي طبقت في الدراسات، وأيضا التعقيب على النتائج التي ستكثف عنها الدراسة الحالية. 


\section{الجمعية المصرية للقر اعة و المعرفة عضو الجمعية الدولية للمعرفة ILA}

منهج الدراسة: تستخدم الدراسة المنهج الوصفي التحليل لتفسير ووصف الظروف والعلاقات التي توجد بين الوقائع، وتحديد الممارسات السائدة، ومن ثم التحليل الدقيق الذي يقود الباحث الي استخلاص العلاقات والاستتناجات المتضمنة لمشكلة البحث. مجتمع الاراسة: مجتمع الدراسة يعرف بأنه جميع مفردات الظاهرة التي يدرسها الباحث،

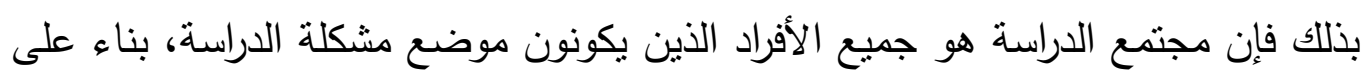
مشكلة الدراسة وأهدفها. عينة الدراسة:

جدول مجتمع و عينة الدر اسة والاستمار ات الموزعة

\begin{tabular}{|c|c|c|c|c|}
\hline الاستمارات القابلة للتحليل & الاستمارات غير المستردة و & الاستمارات & الداسة & الموزعة المتمارات \\
\hline$v$. & v & v. & vv & VV \\
\hline
\end{tabular}

ع - أداة الدراسة: تكونت استمارة الاستبيان من المحاور التالية: ا ـ التخطيط الإلكتروني ويشتمل على ( • () فقرة. r. التتظيم الإلكتروني ويشتمل على (T ( ) فقرة.

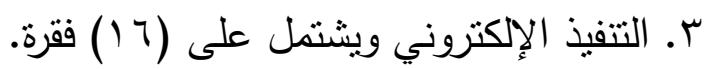
ع. الرقابة والتقويم الإلكتروني و يشتمل على (ع الـ ) فقرة. جدول ب دراجات مقياس ليكرث الخماسي

\begin{tabular}{|c|c|c|c|c|c|}
\hline غير موافق تمامًا & غير موافق & إلى حد ما & موافق & موافق تمامًا & الاستجابة \\
\hline 1 & $r$ & $r$ & $\varepsilon$ & 。 & الدرحة \\
\hline
\end{tabular}

وبذللك يكون الوزن النسبي لكل درجة استجابة في هذه الحالة هو (•r\%) يتتاسب مع هذه الاستجابة، وتم حساب مدى المقياس الخماسي المستخدم للمحور الكلي في الدراسة كما يلي: حساب المدى = (0-1)/

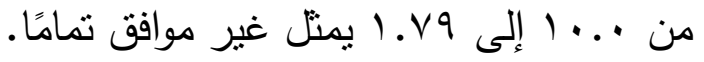




\section{ILA الجمعية المصرية للقر اءة والمعرفة عضو الجمعية الدولية للمعرفة}

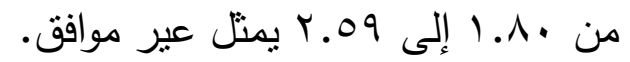

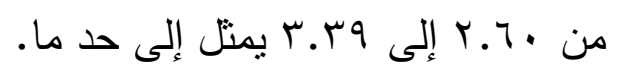

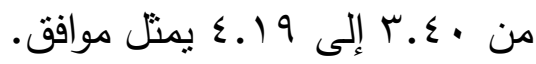

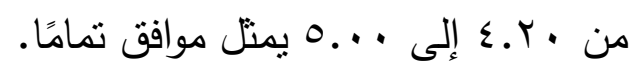

صدق الاستبيان: يقصد بصدق الاستبيان أن تقيس أسئلة الاستبيان فيما وضعت لقياسه، وقد قام الباحث بالتأكد من صدق الاستبيان: صدق المحكمين "الصدق الظاهري": قبل اعتماد استمارة الاستبيان من قبل الباحث، ما مان تضمنته من أسئلة كان لا بد من اختبار صدق المقياس وقياس ثبات استمارة الاستبيان. أ- اختبار صدق المقياس: الأداة الصادقة هيا لأداة التي تقيس ما صممت من أجل قياسه والمقصود بصدق الأداة هو صدق النتائج التي يتم جمعها، أو التوصل إليها باستخدام تلاك الأداة، من أجل اختبار صدق استمارة الاستبيان فقد تم عرض استمارة الاسنبيان المخصصة للبحث الميداني على الأساتذة والخبراء المختصين في هذا المجال

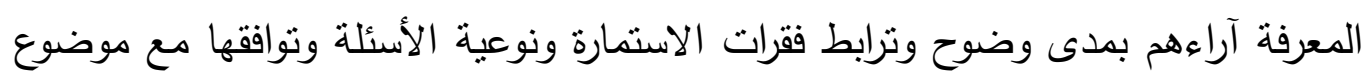
الدراسة.

فبعد إعداد استمارة الاستبيان في صورتها المبدئية نم عرضها على السادة المحكمين وذلك للتحقيق من:

1- مناسبة الأداة للهدف الذي صممت من أجله. r - سلامة صياغة المفردات ووضوحها. r- حذف أو إضافة ما يراه السادة المحكمون مناسبا من مفردات أو تعديلها، في ضوء الملاحظات التي أبداها السادة المحكمين أجريت التعديلات اللازمة لتأخذ الاستمارة صورتها النهائية. 


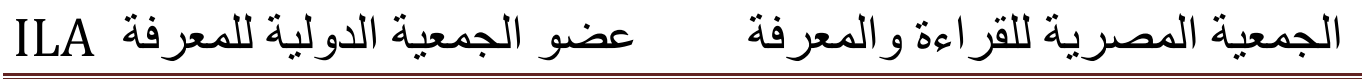

\section{أولا- الصدق والثبات لأبعاد الاستبانة:}

Reliability معامل ثبات ألفا كرونباخ الفاد الهنات

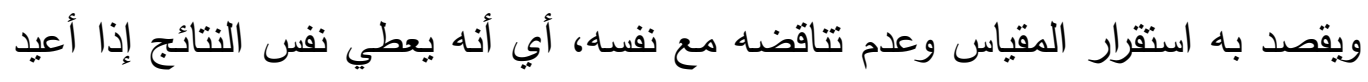

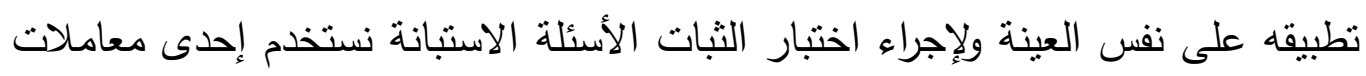

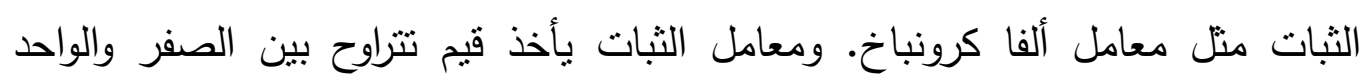

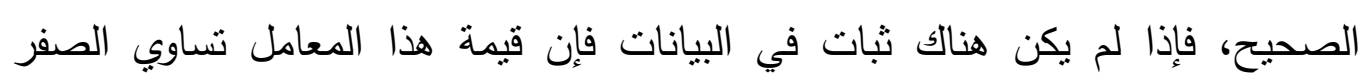

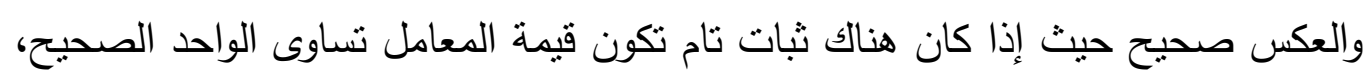

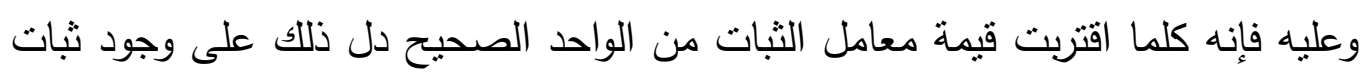
في البيانات (استجابات أفراد العينة).

ويقصد بثبات أداة القياس أن بعطي النتائج نفسها إذا أعيد نطبيق الاستبانة على نفس النس

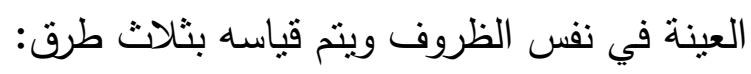
1- الطريقة الأولى: الاختبار واعادة الاختبار يتم في هذه الطريقة نطبيق الاستبانة على فئل

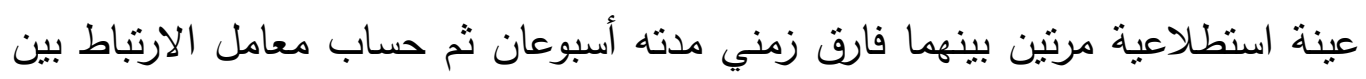

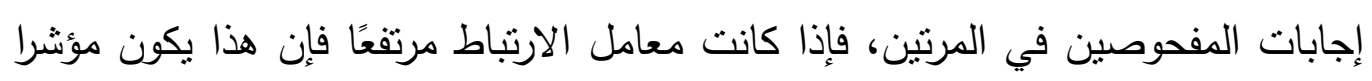

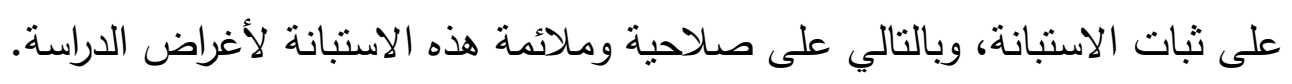

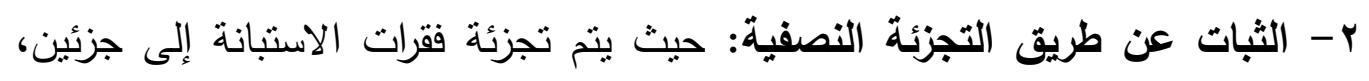

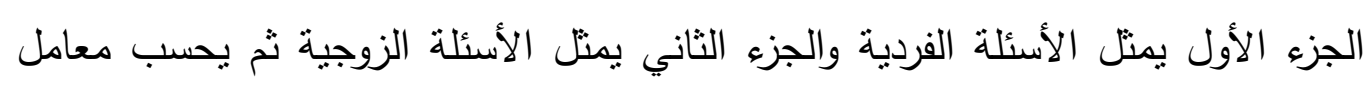
الارتباط (r) بين درجات الأسئلة الفردية ودرجات الأسئلة الزوجية ثم تصحيح معامل الألئل الارتباط بمعادلة بيرسون براون. ب- معامل ثبات كرونباخ الفا. معامل الصدق Validity: ويقصد به أن المقياس يقيس ما وضع لقياسه ويمكن حسابه رياضيا من خلا الجذر التربيعي لمعامل الثبات. 


\section{ILA الجمعية المصرية للقر اءة والمعرفة عضو الجمعية الدولية للمعرفة}

\section{يتم حساب معامل ثبات ألفا كرونباخ باستخدام برنامج (22) SPSS VR}

جدول r معاملات الثبات والصدق لمحاور الدراسة

\begin{tabular}{|c|c|c|c|}
\hline معامل الصدق & معامل الثبات & عدد الفقرات & محاور الاراسة \\
\hline $.9 \leq r$ &.$\wedge \wedge \wedge$ & 1. & التخطبط الإلكتروني \\
\hline .907 & $.91 \leq$ & 17 & التنظيم الإلكتروني \\
\hline .9 Y & .107 & 17 & التتفيذ الإلكتروني \\
\hline $.9 r r$ & .10. & $1 \varepsilon$ & الرقابة و التقويم الإلكتروني \\
\hline $.9 \wedge r$ & $.97 \leq$ & 07 & الإدارة الإلكترونية \\
\hline
\end{tabular}

ويتضح من الجدول السابق قيم معاملات الثبات ألفا كرونباخ الأبعاد الاستبانة وكانت

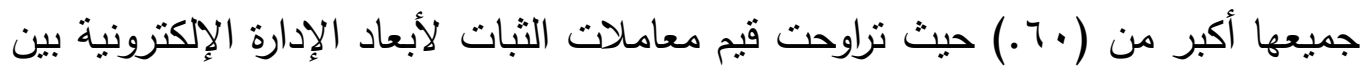

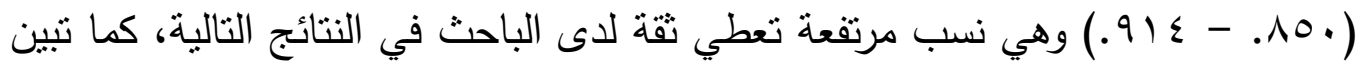

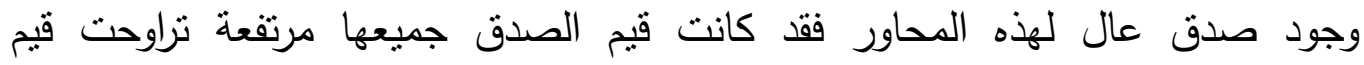

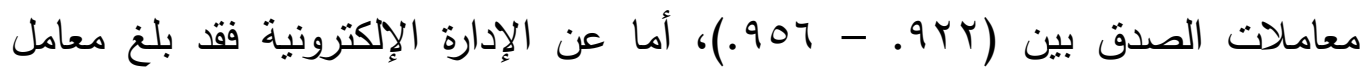

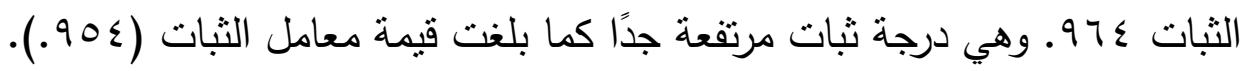

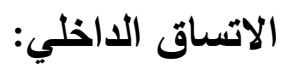
حيث يتم قياس مدى ارتباط و تمثيل الفقرة للمحور الرئيسي له فإذا كان ارتباط الفقرة

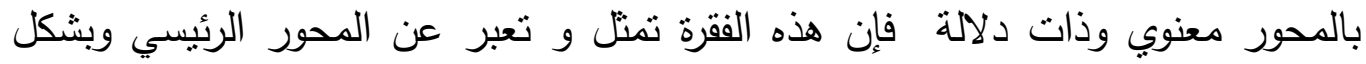
الصدق Validity: الصدق ببساطة هو أن تقيس أسئلة الاستبانة أو الاختبار ما وضعت لقياسه أبي يقيس فعلاً الوظيفة التي يفترض أنه يقيسها.

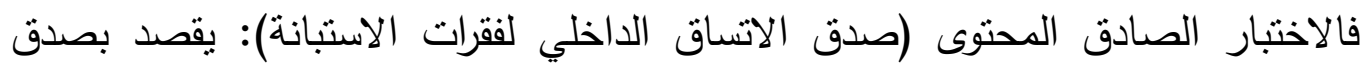

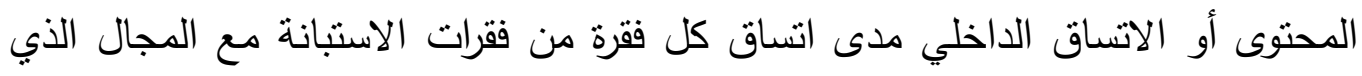
تنتمي إليه هذه الفقرة. 
ويمكن حساب الاتساق الداخلي للاستبانة وذلك من خلال حساب معاملات الارتباط بين كل فقرة من فقرات مجالات الاستبانة والدرجة الكلية للمجال نفسه. المحور الاول - التخطيط الإلكتروني:

جدول ؛ الاتساق الداخلي لفقرات محور التخطيط الإكتروني

\begin{tabular}{|c|c|c|}
\hline 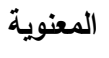 & معامل ارتباط سبيرمان & التخطيط الإكتروني \\
\hline$\ldots$ & $. \neg \wedge \leq * *$ & يؤدي استخدام الغدارة الإككترونية في التخفيف من الإعباء الإدارية المختلفة. \\
\hline$\cdots$ & $.799 * *$ & تعمل الإدارة الإلكترونية على تقليل كلفة إجراءات التخطيط الإداري. \\
\hline$\cdots$ & . ^ヘケ** & يسهل استخدام الإدارة الإلكترونية مواكبة المتغيرات و المستجدات الإدارية \\
\hline$\cdots$ &.$r V T * *$ & تساهم الإدارة الإلكترونية في تطوير نظم التخطيط الإداري. \\
\hline$\cdots$ & .0 个米 & تساعد الإدارة الإلكترونية في إكساب الإداريين العديد من الخبرات الإدارية. \\
\hline$\cdots$ & .乏१广** & تساهم الإدارة الإلكترونية في توفير الخطط الإدارية البديلة عند الحاجة. \\
\hline$\cdots$ &.$\leqslant 0 . * *$ & يؤدي استخدام الإدارة الإلكترونية في تطبيق مفهوم التخطيط المتكامل. \\
\hline$\ldots$ & $.777 * *$ & أفضل. الإدارة الإلكترونية في وضع خطط نوظيف الموارد البشرية و المادية بشكل \\
\hline$\cdots$ & $.700 * *$ & تساهم الإدارة الإلكترونية في إثراك جميع الأطراف في التخطيط الاستراتيجي. \\
\hline$\cdots$ &.$\vee 19 * *$ & تساعد الإدارة الإلكترونية في الحد من مشكلات التخطيط. \\
\hline
\end{tabular}

بتضح من الجدول السابق أن هنالك ارتباط ذات دلالة إحصائية بين فقرات التخطيط الإلكتروني والبعد الكلي للتخطيط الإلكتروني عند مستوى ثقة (99.) نراوحت قيم الارتباط

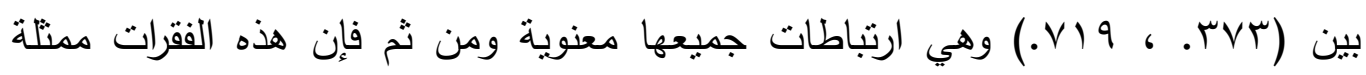
بشكل قوي للمحور الرئيسي التخطيط الإكتروني وتقيس الغرض المرجو منه. المحور الثاني: التنظيم الإلكتروني. 
جدول ه الاتساق الداخلي لفقرات محور التعليم الإلكتروني

\begin{tabular}{|c|c|c|}
\hline 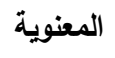 & معامل ارتباط سبيرمان & التنظيم الإكتروني \\
\hline$\cdots$ &.$\varepsilon r r^{*} *$ & تساعد الإدارة الإلكترونية في الحصول على المعلومات في أي وقت ومكان. \\
\hline$\cdots$ & $.01 r * *$ & نوفر الإدارة الإككترونية في نوفير نظام أرشفة إلكترونية للختلف الأطراف. \\
\hline$\cdots$ &.$£ १ \vee * *$ & تساهم الإدارة الإلكترونية في توفير الوقت والمال والجهد. \\
\hline$\cdots$ & $.701 * *$ & نوفر الإدارة الإلكترونية عناء الانتقال عبر الإدارات لإنجاز المعاملات. \\
\hline$\cdots$ & $. \Gamma \leqslant \wedge * *$ & تساهم الإدارة الإككترونية في تتظيم عملية تسجيل المواد الدراسية. \\
\hline$\cdots$ & 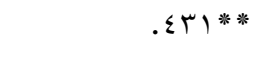 & تعمل الإدارة الإككترونية على تسهيل عملية التوجيه لمختلف الأطراف الإدارية. \\
\hline$\cdots$ & $.0 r$ r * * & تساهم الإدارة الإلكترونية في تأمين التواصل بين مختلف العناصر الإدارية. \\
\hline$\cdots$ & .7 . $0 * *$ & تساعد الإدارة الإلكترونية في استيعاب أكبر عدد ممكن من المستفيدين في وقت \\
\hline$\ldots$ &.$r r V * *$ & تساعد الإدارة الإلكترونية في كسر حاجز الرونين في إجراء المعاملات المختلفة. \\
\hline$\cdots$ & $.09 V^{*} *$ & تساهم الإدارة الإلكترونية في رفع مستوى تطبيق إدارة شؤون الطلبة. \\
\hline$\cdots$ & $.09 \Lambda * *$ & تساهم الإدارة الإلكترونية في نوفير فرص الاطلاع على جداول المواد الدراسية. \\
\hline$\cdots$ & $.0 Y r * \%$ & تساعد الإدارة الإلكترونية في تنظيم الاجتماعات إلكترونيًا. \\
\hline$\cdots$ & $.0 \leqslant 0 * *$ & تساهم الإدارة الإلكترونية في إيجاد بيئة تتظيمية تتسم بالدقة. \\
\hline$\cdots$ &.$\sum \vee V^{*} * *$ & تساعد الإدارة الإلكترونية في توفير مبدأ الخصوصية لدى مختلف الاطراف. \\
\hline$\cdots$ &.$\leqslant 79 * *$ & تساهم الإدارة الإلكترونية في تحقيق التواصل مع أولياء أمور الطلاب إلكترونيًا. \\
\hline$\ldots 1$ & $.0 \leqslant 0 * *$ & الإلكتروني. \\
\hline
\end{tabular}

يتضح من الجدول السابق أن هناك ارتباط ذات دلالة إحصائية بين فقرات التنظيم الإكتروني والبعد الكلي للتنظيم الإلكتروني عند مستوى ثقة (99.) تراوحت قيم الارتباط

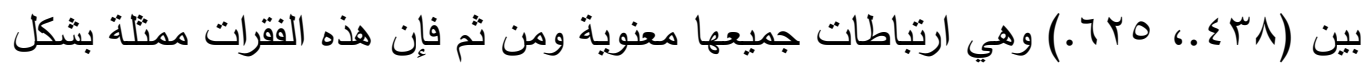
قوي للمحور الرئيسي للتنظيم الإكتروني وتقيس الغرض المرجو منه. 
المحور الثالث: التنفيذ الإكتروني.

جدول ج الاتساق الداخلي لفقرات محور التنفيذ الإلكتروني الإلفروبي

\begin{tabular}{|c|c|c|}
\hline 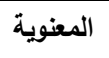 & معامل ارتباط سبيرمان & التنفيذ الإكتروني \\
\hline$. r \leq$ &.$r T \wedge * \%$ & تعمل الإدارة الإكترونية على توفير البيانات لدى جميع المستفيدين من خدمات الوزارة. \\
\hline$\ldots$ & .0 . Y ** & تساعد الإدارة الإلكترونية في التخلص من النظام البيروقراطي في إنجاز المعاملات. \\
\hline$\ldots r$ &. Y०\** & تساهم الإدارة الإككترونية في تأدية الوزارة لوظيفتها التزبوية و المجتمعية. \\
\hline$\ldots$ & $.040 \%$ & تصالأساليب الجديدة اللتي تحسن من ألإدترونية القيادات على الإستجابة للمستجدات والإبداع وتجريب الأفكار \\
\hline$\cdots$ & $.7 イ \div *$ & تساعد الإدارة الإكترونية في تتفيذ العديد من الخطط الإدارية بسهولة و يسر. \\
\hline$\cdots$ &.$\leqslant 10 \%$ & تعمل الإدارة الإلكترونية على تقديم المعلومات بشكل دقيق و سليم. \\
\hline$\ldots$ & $.0 \mathrm{r}$ \%*\% & الإكوندي استخدام الإدارة الإكترونية في دعم القيادات لتحقيق مراكز متقدمة في الإدارة \\
\hline$\cdots$ & $.0 \cdot 1 * *$ & تساعد الإدارة الإككترونية في الاستغلال الأمتل لمصادر المعلومات المتاحة. \\
\hline$\cdots$ & $.0 .7 \% *$ & تساهم الإدارة الإلكترونية في تسهيل عملية الحصول على الوثائق و المعاملات الرسمية. \\
\hline$\cdots$ & 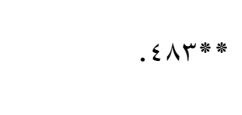 & تساعد الإدارة الإككترونية في تحسين الأداء الإداري في جميع التعاملات مع أولياء أمور \\
\hline$\cdots$ & $.0 \mathrm{rV} * *$ & تعمل الإدارة الإلكترونية على الحد من تأثير العلاقات الثخصية في إنهاء المعاملات. \\
\hline$\ldots$ & $.7 r \cdot \% *$ & (الدورات - الندوات - المؤتمرات). للإداراتيين والمعلمين الاطلاع على مصادر المعلومات العالمية \\
\hline$\ldots$ & .VKI\%* & تساعد الإدارة الإلكترونية في تحقيق مبدأ الثفافية في تقديم الخدمات. \\
\hline$\ldots$ &.$r 9 V^{*} * *$ & توفر الإدارة الإكترونية الكثير من المرونة والسرعة في تقديم الخدمات. \\
\hline$\cdots$ &.$r 9 \Lambda * *$ & تساعلاع ألولياء الأمورة الإلكترونية في تسهيل توزيع القرارات الإدارية بين الددرسة والغدارة التعليمية \\
\hline$\cdots 7$ & 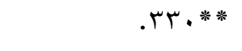 & تساهم الإدارة الإككترونية في سرعة تتفيذ القرارات الإدارية \\
\hline
\end{tabular}

يتضح من الجدول السابق أن هناك ارتباط ذات دلالة إحصائية بين فقرات التنفيذ

الإكتروني والبعد الكلي للنتفيذ الإلكتروني عند مستوى ثقة (99.) تراوحت قيم الارتباط 


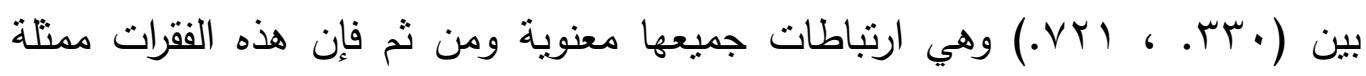
بشكل قوي للمحور الرئيسي التنفيذ الإلكتروني وتقيس الفرض المرجو منه. المحور الرابع: الرقابة والتقويم الإلكتروني. جدول v الاتساق الداخلي لفقرات محور الرقابة و التقويم الإكتروني

\begin{tabular}{|c|c|c|}
\hline 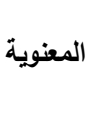 & سبيرمان & الرقابة و التقويم الإكتروني \\
\hline$\ldots$ &.$\leqslant \curlyvee 9 \% *$ & تساهم الإدارة الإلكترونية في تطبيق نظام تدقيق مالي منطور • \\
\hline$\ldots$ & .ノ々ะ** & تساعد الإدارة الإلكترونية في متابعة الخطط و الأعمال اليومية. \\
\hline$\ldots r$ & $.0 \wedge$ \% & ترود الإدارة الإككترونية القيادات التعليمية بالتقارير و البيانات الإحصائية. \\
\hline$\cdots$ & . & تساهم الإدارة الإلكترونية في توفير نظام رقابي إلكتروني وفقًا للوائح و التعليمات بالوزارة. \\
\hline$\ldots$ & $. \leqslant 0 \leqslant * \%$ & تساهم الإدارة الإكترونية في استخدام الأسلوب العلمي في عمليات القويم. \\
\hline$\ldots$ &.$\Sigma 1 \cdot * * *$ & تساهم الإدارة الإلكترونية في تقييم إنجاز الأعمال وجودتها. \\
\hline$\ldots$ &.$\Sigma \Upsilon^{*} * * *$ & تساهم الإدارة الإككترونية في تحديث المعلومات والبيانات من خلد الرقابة والمتابعة. \\
\hline$\cdots$ & $.0 . r^{* * *}$ & تساعد الإدارة الإلكترونية في الكثف عن نقاط القوة لتعزيزها، ونقاط الضعف لعلاجها في العمل \\
\hline$\cdots$ &.$\Sigma 9 \vee * *$ & تساهم الإدارة الإلكترونية في تطبيق نظام رقابة منطور . \\
\hline$\ldots$ & $.0 \vee 7 * \%$ & تساهم الإدارة الإلكترونية في تزويد القيادات التعليمية والعاملين بالوزارة بالتغذية الراجعة و التقويم \\
\hline$\ldots$ & $.070 \% *$ & ترسخ الإدارة الإكترونية مبدأ المتابعة والرقابة الذاتية للمهمات الإدارية. \\
\hline$\ldots$ &.$\leqslant \nearrow . * *$ & توفر الإدارة الإلكترونية طرق دقيقة لمتابع ومراقبة الأعمال الإدارية. \\
\hline$\cdots$ & .乏) 个** & تناعد الإدارة الإلكترونية في توفير المتابعة والتقويم لمختلف المجالات الإدارية. \\
\hline$\ldots$ & $.00 \gamma^{*} *$ & تساهم الإدارة الإلكترونية في إيجاد وسائل متتوعة لتقييم العمل الإداري. \\
\hline
\end{tabular}

يتضح من الجدول السابق أن هناك ارتباط ذات دلالة إحصائية بين فقرات الرقابة والتقويم الإككتروني والبعد الكلي للرقابة والتقويم الإلكتروني عند مستوى ثقة (99.) تراوحت

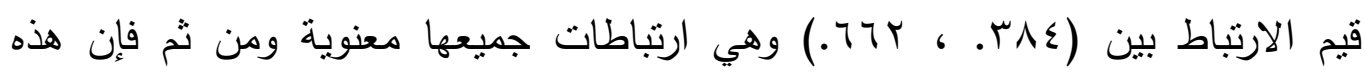


الفقرات ممنلة بشكل قوي للمحور الرئيسي للرقابة والتقويم الإلكتروني وتقيس الغرض

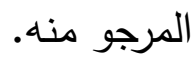

\section{المقاييس الوصفية:}

بعد أن تم استعراض الخصائص الديموجرافية والثخصية سيتتاول الباحث المقاييس الأساسية لمحاور الدراسة و متغيراتها من خلال تعرف اتجاهات الآراء لدى أفراد العينة بالنسبة لفقرات محاور الدراسة والأهمية النسبية لها. أولًا - التخطيط الإلكتروني:

جدول ^ الوصفية لفقرات محور التخطيط الإكتروني

\begin{tabular}{|c|c|c|c|c|}
\hline الأهمية & معامل & الانحراف & المتوبط & التخطيط الإكتروني \\
\hline$\% \vee 0 . \wedge 1$ & $\% 17.7 \leq$ & 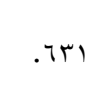 & r.vт & المؤدي استخدام الإدارة الإلكترونية في التخفيف من الأعباء الإدارية \\
\hline$\%$ \%r.or & $\% \backslash \vee . 乏 9$ & $.7 \leqslant$ & r.71 & تعمل الإدارة الإككترونية على تقليل كلفة إجراءات التخطيط الإداري. \\
\hline$\% \vee \varepsilon . \varepsilon \wedge$ & $\%$ IV.rV & $.7 \leq r$ & r.Vt & الإدارية العالمية. استخدام الإدارة الإلكترونية مواكبة المتغيرات والمستجدات \\
\hline$\% \vee 1 . \leqslant r$ & $\%$ IV.VT & 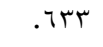 & r.ov & تساهم الإدارة الإلكترونية في تطوير نظم التخطيط الإداري. \\
\hline$\% \vee \varepsilon . \wedge \uparrow$ & $\% 17.17$ & .7 .0 & r.v & الإدارية. الإدارة الإلكترونية في إكساب الإداريين العديد من الخبرات \\
\hline$\% \vee 1 .$. & $\% \backslash \vee . \vee \leq$ & . & $r .00$ & الحاجة. الإدارة الإلكترونية في توفير الخطط الإدارية البديلة عند \\
\hline$\% \vee 0.7 r$ & $\% 10.00$ & $.0 \wedge \wedge$ & r.vA & المؤدي استخدام الإدارة الإلكترونية في تطبيق مفهوم التخطيط \\
\hline$\% V Y . O V$ & $\% \backslash \wedge .+r$ & $.70 \leqslant$ & 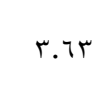 & العادية بشكل الإدارة الإكترونية في وضع خطط توظيف الموارد البشرية و \\
\hline$\% \vee 7.19$ & $\% \backslash \vee .11$ & $.70 r$ & r.^I & الاستراتيجي. الإدارة الإلكترونية في اشتراك جميع الأطراف في التخطيط \\
\hline$\% \vee \leq .7 \vee$ & $\%$ \% V.or & $.70 \leqslant$ & r.vr & تساعد الغدارة الإككترونية في الحد من مشكلات التخطيط. \\
\hline$\% \vee \varepsilon \ldots .7$ & $\% 11.1 \leq$ & $\cdot \varepsilon \operatorname{lt}$ & $r \cdot v \cdot r$ & التخطيط الإلكتروني. \\
\hline
\end{tabular}




\section{ILA الجمعية المصرية للقر اءة والمعرفة عضو الجمعية الدولية للمعرفة}

ويوضح الجدول السابق بعض المقاييس الإحصائية الأساسية لفقرات محور التخطيط الإلكتروني وأيضًا المحور الكلي ومن خلال قيم المتوسطات الحسابية نجد أن آراء أفراد العينة قد اتجهت جميعها نحو الموافقة لفقرات المحور حيث تراوحت قيم الوسط الحسابي بين (00.ب - 1. 1. للفقرات (تساهم الإدارة الإلكترونية في توفير الخطط الإدارية البديلة عند الحاجة، تساهم الإدارة الإكترونية في اثتراك جميع الاطراف في التخطبط الاستراتيجي) كما أوضحت النتائج عدم وجود اختلافات كبيرة بين الآراء لدى أفراد العينة حيث تراوحت قيم معامل الاختلاف بين (10.00 - r ب.11) كما تراوحت قيم الأهمية

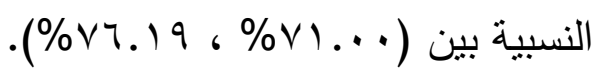

أما على مستوى المحور الكلي (التخطيط الإلكتروني) فقد نبين أن متوسط أراء أفراد

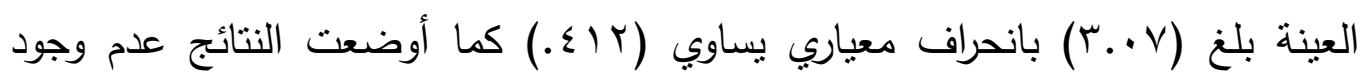
اختلافات كبيرة على مستوى المحور حيث بلغ معامل الاختلاف (ع ا. (1\%) مما يشير ذلك إلى أن هنالك اتفاق و اجماع بين أراء أفراد العينة بالموافقة على أهمية محور

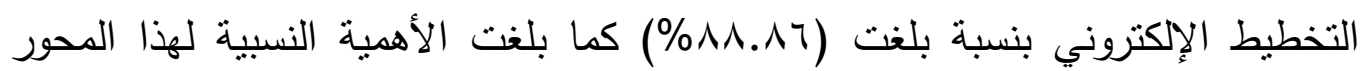

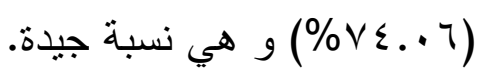
ثانيًا - التنظيم الإلكتروني: جدول 9 المقاييس الوصفية لفقرات محور التنظيم الإلكتروني

\begin{tabular}{|c|c|c|c|c|}
\hline الألمبية & 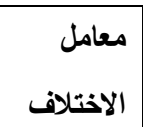 & الانحراف المعياري & المتوسط & التنظيم الإكتروني \\
\hline$\%$ \%r.19 & $\% 17.04$ & .097 & $r .71$ & في أي وقت ومكاندان. الإلكترونية في الحصول على المعلومات \\
\hline$\% \vee r . l \varepsilon$ & $\% \backslash \wedge . \mid r$ & אדי. & r.T4 & لمختلف الاططراف. تلإلكترونية في توفير نظام أرشفة إلكترونية \\
\hline$\% \vee r . q$. & $\% 17 . \wedge r$ & אזT. & r.v. & تساهم الإدارة الإككترونية في توفير الوقت والمال و \\
\hline
\end{tabular}




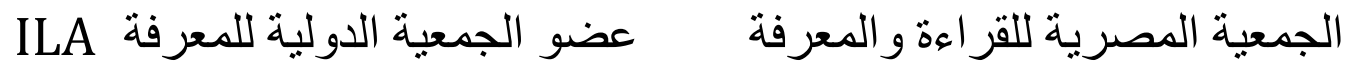

\begin{tabular}{|c|c|c|c|c|}
\hline$\%$ \%r.or & $\%) \vee . \leqslant q$ & $.7 \leqslant r$ & r.१人 & لوفر الغدارة الإلكترونية عناء الانتقال عبر الإدارات \\
\hline \%VY.OV & $\% \backslash 0 .\{1$ & .009 & r.tr & تالدراسية. الإدارة الإلكترونية في تتظيم عملية تسجيل المواد \\
\hline$\% \vee q . \varepsilon r$ & \%\ᄉ.T. &.$V T V$ & r.9V & تعمل الإدارة الإلكترونية على تسهيل عملية التوجيه \\
\hline \%Vq.7r & $\% \backslash \wedge . \leqslant \Gamma$ & .VT & r.9人 & تساعد الإدارة الإلكترونية في تأمين التواصل بين مختلف \\
\hline \%Vr.or & $\% \backslash \wedge . \Upsilon \wedge$ &.$T V Y$ & r.१^ & تساعد الإدارة الإلكترونية في استيعاب أكبر عدد ممكن \\
\hline$\% \vee \cdot . r q$ & $\% 17 . \vee 9$ & .09 & r.01 & تساعد الإدارة الإكترونية في كسر حاجز الروتين في \\
\hline$\%$ \%r.or & $\% 19 . .0$ &.$\vee \cdots$ & r.71 & تساهم الإدارة الإلكترونية في رفع مستوى نطبيق إدارة \\
\hline 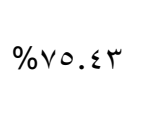 & $\% \backslash \wedge .11$ & ת & $r . V V$ & تساهم الإدارة الإلكترونية في نوفير فرص الاطلاع على المى الدراسية. \\
\hline \%VY.r人 & \%IV.VY & $.7 \leqslant 1$ & T.TT & تالتعاعد الإدارة الإلكترونية في تنظيم اجنماعات القيادات \\
\hline 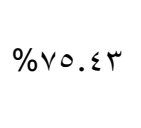 & $\% 17.1 \leq$ & .7 .9 & $r . V V$ & تسالدم الإدارة الإلكترونية في إيجاد بيئة تنظيمية تتسم \\
\hline$\% \vee 1 . .0$ & $\% \mid v . .1$ & $.7 \cdot \varepsilon$ & $r .00$ & تساعد الإدارة الإلكترونية في نوفير مبدأ الخصوصية لدى \\
\hline$\% \vee \leqslant . r q$ & $\%$ IV.Vq & .741 & $r . v 1$ & تساهم الإدارة الإلكترونية في تحقيق التواصل مع أولياء \\
\hline$\% \vee r .90$ & $\% \backslash \leq . Y Y$ & .019 & r.7o & توفر الإدارة الإلكترونية لكل طالب رقم تعريفي إلكتروني \\
\hline$\% \vee r .90$ & $\%$ \%.レА & תודיט & $r .791$ & التنظيم الإلكتروني. \\
\hline
\end{tabular}


ويوضح الجدول السابق بعض المقاييس الإحصائية الأساسية لفقرات محور التنظيم الإلكتروني وأيضا المحور الكلي ومن خلال قيم المتوسطات الحسابية نجد أن آراء أفراد العينة قد اتجهت جميعها نحو الموافقة لفقرات المحور حيث نراوحت قيم الوسط الحسابي بين (1.01. - 91.ب) للفقرات (تساعد الإدارة الإككترونية في كسر حاجز الروتين في إجراء المعاملات المختلفة، ساهم الإدارة الإككترونية في تأمين التواصل بين مختلف العناصر الإدارية) كما أوضحت النتائج عدم وجود اختلافات كبيرة بين الآراء لدى أفراد

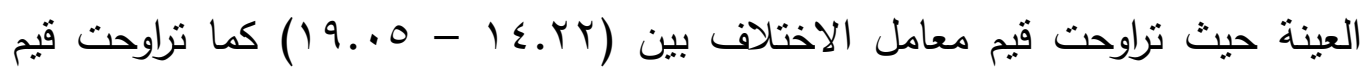

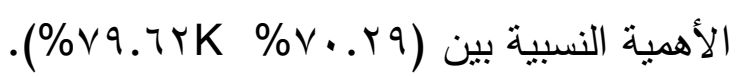

أما على مستوى المحور الكلي (التتظيم الإكتروني) فقد تنين أن متوسط آراء أفراد العينة بلغ (99.r) بانحراف معياري يساوي (Y7\%.) كما أوضحت النتائج عدم وجود اختلافات

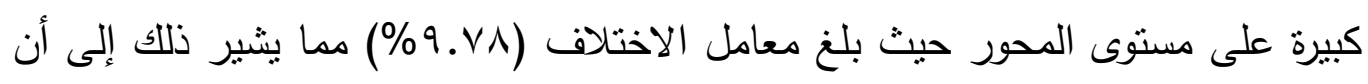
هناك اتفاق واجماع بين آراء أفراد العينة بالموافقة على أهمية محور التتظيم الإكتروني

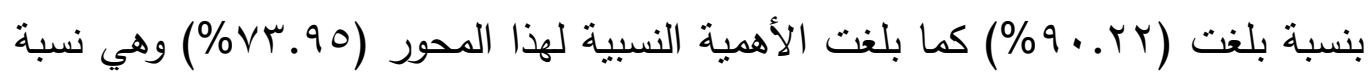

جيدة.

ثالثًا - التنفيذ الإكتروني:

جدول •ا المقاييس الوصفية لفقرات محور التنفيذ الإلكتروني

\begin{tabular}{|c|c|c|c|c|}
\hline الأهمية & معامل & الانمراف - المعياري & 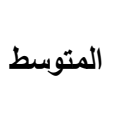 & التفيذ الإكتروني \\
\hline$\% \vee \leq .1$ & $\%) r . \Sigma 7$ &.$\leqslant 99$ & T.V. & 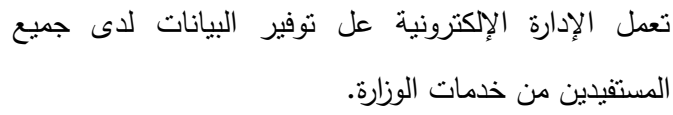 \\
\hline$\% \vee Y . \vee T$ & $\%$ IV.or & . & T.Tะ & في إنجاز المعاملات. الإدارة الإكترونية في التخلص من النظام البيروقراطي \\
\hline$\% \vee \varepsilon . \varepsilon \wedge$ & $\% 1 \leq .77$ & $.0 \leqslant 7$ & T.VT & تساهم الإدارة الإلكترونية في تأدية الوزارة لوظيفتها التربوية و \\
\hline \%VYrA & $\% \backslash \wedge .9 r$ & .710 & r.7r & تساعد الإدارة الإلكترونية القيادات التعليمية على الاستجابة \\
\hline
\end{tabular}




\begin{tabular}{|c|c|c|c|c|}
\hline & & & & تلحسن من أداءها الإداري. والإبداع وتجريب الأفكار والأساليب الجديدة التي \\
\hline$\% \vee r . \ldots$ & $\% \backslash v . .0$ & $.71 \leqslant$ & r.7. & تساعد الإدارة الإلكترونية في تنفيذ العديد من الخطط الإدارية \\
\hline \%VY.VT & $\% 17.7 V$ & .7 .7 & $r . T \varepsilon$ & تعليم الإدارة الإلكترونية على تقديم المعلومات بشكل دقيق و \\
\hline$\% \vee \cdot .7 v$ & $\% \backslash V .1 \leq$ & 7.7 & r.or & لتحؤدي استخدام الإدارة الإكترونية في دعم القيادات التعليمية \\
\hline$\% \vee \leq . \leq \wedge$ & $\% 1 \vee .77$ & .701 & r.Vr & تساعد الإدارة الإلكترونية في الاستغلال الأمثل لمصادر \\
\hline 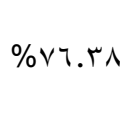 & $\% 10 . \vee \leqslant$ & .7 .1 & r.Ar & تساههم الإدارة الإلكترونية في تسهيل عملية الحصول على \\
\hline$\% \vee r . l \leq$ & $\% \backslash \wedge . \mid r$ & אדצד. & T.74 & تساعد الغدارة الإلكترونية في تحسين الأداء الإداري في جميع \\
\hline$\% \vee \varepsilon . \varepsilon \wedge$ & $\% 17 . \wedge 7$ & . TrA & $r . v r$ & 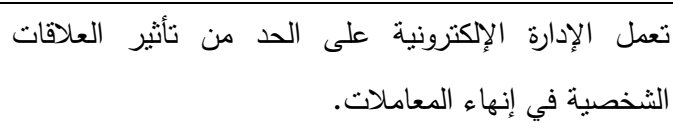 \\
\hline$\% \vee r . q$. & $\% \backslash \wedge . \wedge \mid$ & .790 & r.v. & 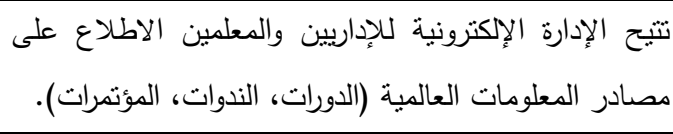 \\
\hline$\% \vee r . q$. & $\% 1 \vee .70$ & .704 & r.v. & تشاعد الإدارة الإككترونية في تحقيق مبدأ الثفافية في تقديم \\
\hline 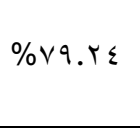 & $\% 10.7 r$ & .719 & $r .97$ & تقوفر الإدارة الإلكترونية الكثير من المرونة و السرعة في \\
\hline$\% \vee 9 . \wedge 1$ & \%IV.r. & ד & $r .99$ & تباعد الإدارة الإككترونية في تسهيل نتوزيع القرارات الإدارية \\
\hline$\% \vee \wedge . T \vee$ & $\% 17.7 \varepsilon$ & $.70 \leqslant$ & r.qr & تساهم الإدارة الإلكترونية في سرعة تتفيذ القرارات الإدارية. \\
\hline$\% \vee \varepsilon .0 V$ & $\%$ \%.ห० & $. r \leq 0$ & r.VYq & التنفيذ الإكتروني. \\
\hline
\end{tabular}


ويوضح الجدول السابق بعض المقاييس الإحصائية الأساسية لفقرات محور التنفيذ الإلكتروني وأيضًا المحور الكلي ومن خلال قيم المتوسطات الحسابية نجد أن أراء أفراد العينة قد اتجهت جميعها نحو الموافقة لفقرات المحور حيث تراوحت قيم الوسط الحسابي

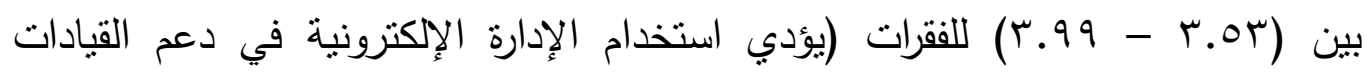
التعليمية لتحقيق مراكز منقدمة في الأداء الإلكتروني بين إدارات التعليم، تساعد الإدارة

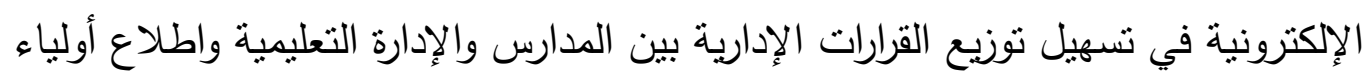
الأمور على ما يخصهم من تلك القرارات على الموقع الإلكتروني للوزارة) كما أوضحت النتائج عدم وجود اختلافات كبيرة بين الآراء لدى أفراد العينة حيث تراوحت قيم الإكتئ معامل

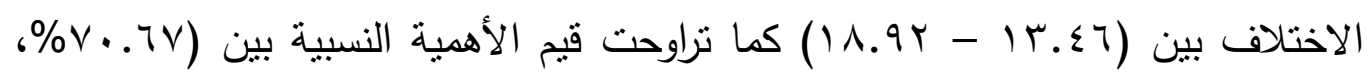
.$(\% \vee 9 . \wedge)$

أما على مستوى المحور الكلي (التتفيذ الإكتروني) فقد تبين أن متوسط أراء أفراد

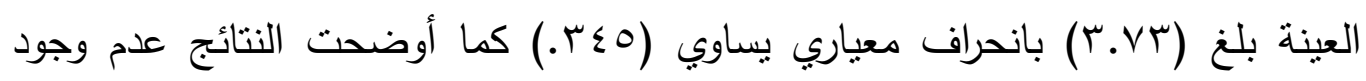
اختلافات كبيرة على مستوى المحزر حيث بلغ معامل الاختلاف (0.9.9\%) مما يشير ذلك إلى أن هنالك اتفاق و إجماع بين أراء أفراد العينة بالموافقة على أهمية محور التنفيذ

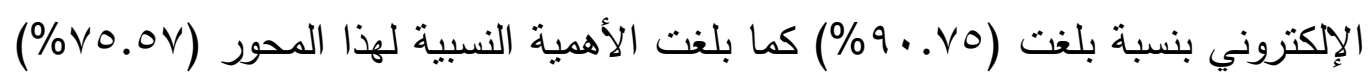
وهي نسبة جيدة.

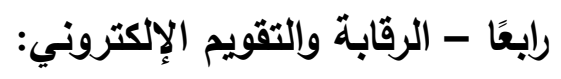

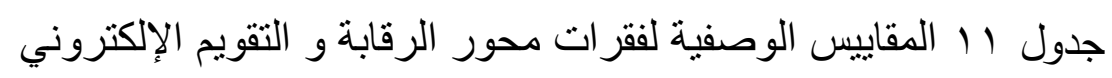

\begin{tabular}{|c|c|c|c|c|}
\hline الأهمية & معامل & الانحراف & المتوسط & الرقابة و التقويم الإلكتروني \\
\hline$\% \wedge . . \Gamma \wedge$ & $\%)$ r.q. & .019 & $\varepsilon .+r$ & تساهم الإدارة الإلكترونية في تطبيق نظام تدقيق مالي متطور . \\
\hline$\% \vee 9.11$ & $\% 1 \leq .90$ & .097 & r.99 & تساعد الإدارة الإلكترونية في متابعة الخطط والأعمال اليومية. \\
\hline$\% \wedge 1.1 \leqslant$ & $\% 1 \Gamma .17$ & $.0 r \varepsilon$ & $\varepsilon . .7$ & نزود الإدارة الإلكترونية القيادات التعليمية بالتقارير والبيانات الإحصائية. \\
\hline \%Vr.or & $\% \backslash \vee . \leqslant q$ & r & r.T人 & تساهم الإدارة الإلكترونية في توفير نظام رقابي إلكتروني وفقًا للوائح \\
\hline
\end{tabular}




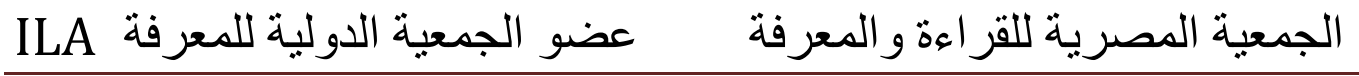

\begin{tabular}{|c|c|c|c|c|}
\hline$\% \vee \varepsilon . \varepsilon \varepsilon$ & \%\Y.YY & . $T \leqslant r$ & T.VT & تساهم الإدارة الإكترونية في استخدام الأسلوب العلمي في عمليات \\
\hline$\%$ \%।.r & $\% \backslash \vee . \wedge 1$ & ع ז & r.07 & تساهم الإدارة الإككترونية في تقييم إنجاز الأعمال و جودتها \\
\hline $72.19 \%$ & $16.52 \%$ & .596 & 3.61 & تساهم الإدارة الإلكترونية في تحديث المعلومات والبيانات من خال \\
\hline $73.14 \%$ & $18.12 \%$ & .663 & 3.66 & 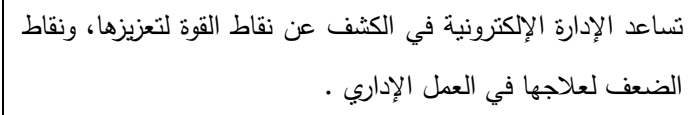 \\
\hline $73.71 \%$ & $16.96 \%$ & .625 & 3.69 & تساهم الإدارة الإلكترونية في تطبيق نظام رقابة منطور · \\
\hline $72.76 \%$ & $17.52 \%$ & .637 & 3.64 & 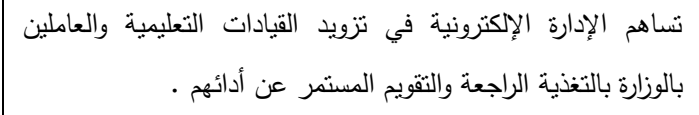 \\
\hline $75.05 \%$ & 16. $44 \%$ & .617 & 3.75 & ترسخ الإدارة الإكترونية مبدأ المتابعة والرقابة الذاتية للمهمات \\
\hline $70.86 \%$ & $17.07 \%$ & .605 & 3.54 & توفر الإدارة الإلكترونية طرق دقيقة لمتابعة ومراقبة الأعمال الإدارية. \\
\hline $75.43 \%$ & $15.71 \%$ & .593 & 3.77 & تساعد الإدارة الإلكترونية في توفير المتابغة والثقويم لمختلف \\
\hline $72.76 \%$ & $17.93 \%$ & .652 & 3.64 & الإداري ت الإدارة الإككترونية في إيجاد وسائل منتوعة لنقييم العمل \\
\hline $74.75 \%$ & $8.73 \%$ & 0.326 & 3.737 & الرقابة والتقويم الإكتروني \\
\hline
\end{tabular}

ويوضح الجدول السابق بعض المقاييس الإحصائية الأساسية لفقرات محور الرقابة والتقويم الإكتروني وأيضا المحور الكلي ومن خلال قيم المتوسطات الحسابية نجد أن آراء أفراد العينة قد إتجهت جميعا نحو الموافقة لفقرات المحور حيث تراوحت قيم الوسط

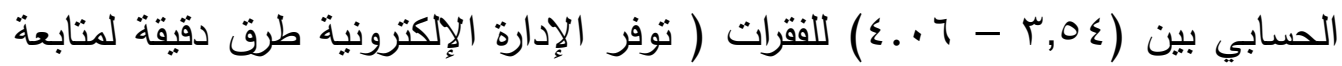
ومراقبة الأعمال الإدارية، تزود الإدارة الإلكترونية القيادات التعليمية بالتقارير والبيانات الإحصائية ) كما أوضحت النتائج عدم وجود اختلافات كبيرة بين الآراء لدى أفراد العينة

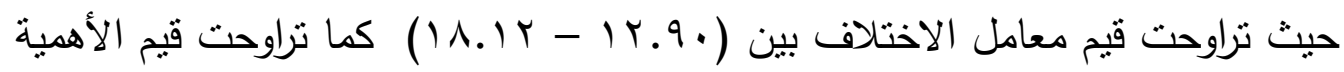

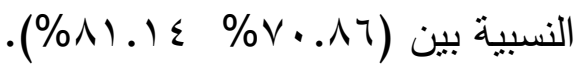
أما علي مستوى المحور الكلي ( الرقابة والتقويم الإلكتروني ) فقد تبين أن متوسط آراء

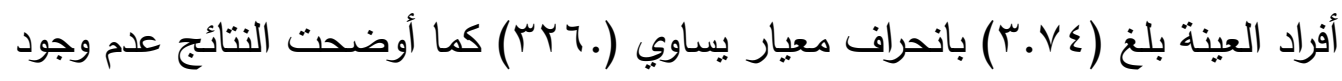




\section{ILA الجمعية المصرية للقر اءة والمعرفة عضو الجمعية الدولية للمعرفة}

اختلافات كبيرة علي مستوي المحور حيث بلغ معامل الاختلاف (8.73\%) مما يشير ذلك إلي أن هناك اتفاق واجماع بين آراء أفراد العينة بالموافقة علي أهمية محور الرقابة

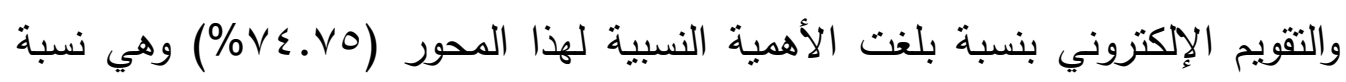
جيدة .

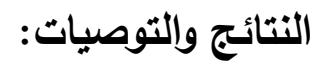
يتتاول هذا الجزء أهم النتائج التي التوصل إليها بعد إجراء الدراسة الميدانية، وبناءً عليه قامت الدراسة بوضع بعض التوصيات، وفيما يلي توضح الدراسة النتائج التي خلصت التهاء

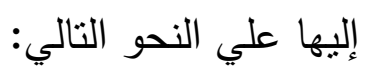

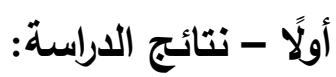

أظهرت النتائج اتجاه استجابات أفراد العينة نحو الموافقة علي أهمية محور التخطيط الإكتروني إلي جانب ذللك تبين وجود اختلافات في الآراء بنسبة بلغت § ا. (1\% وهي أقل من النسبة المقبولة كما بلغت الأهمية النسبية لمحور التخطيط

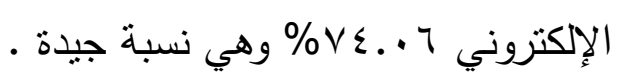

أظهرت النتائج اتجاه استجابات أفراد العينة نحو الموافقة علي أهمية محور التنظيم الإلكتروني إلي جانب ذلك تبين وجود اختلافات في الآراء بنسبة بلغت ^^.9\% وهي أقل من النسبة المقبولة تتبر إلي وجود اتفاق بالموافقة علي هذا المحور بنسبة بلغت r ب. . 9\% كما بلغت الأهمية النسبية لمحور التنظيم الإككتروني 73.95\% وهي نسبة جيدة .

أظهرت النتائج اتجاه استجابات أفراد العينة نحو الموافقة علي أهمية محور الرقابة التنفيذ إلي جانب ذلك تبين وجود اختلافات في الآراء بنسبة بلغت هץ.9 \% وهي أقل من النسبة المقبولة تشير إلي وجود اتفاق بالموافقة علي هذا المحور بنسبة بلغت 


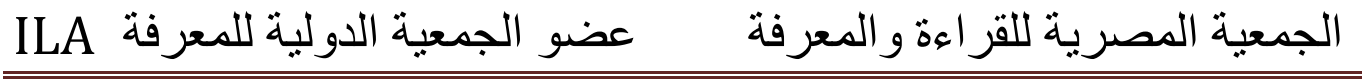

0. . . \% كما بلغت الأهمية النسبية لمحور التنفيذ الإكتروني V V.OV\% وهي نسبة جيدة .

أظهرت النتائج اتجاه استجابات أفراد العينة نحو الموافقة علي أهمية محور الرقابة

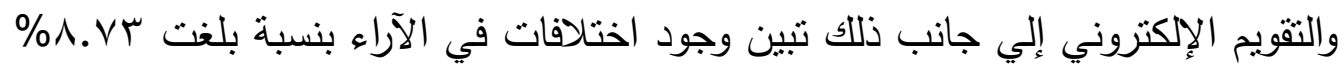
وهي أقل من النسبة المقبولة كما أنها أقل أبعاد الإدارة الإلكترونية اختلافًا يري إلي وجود

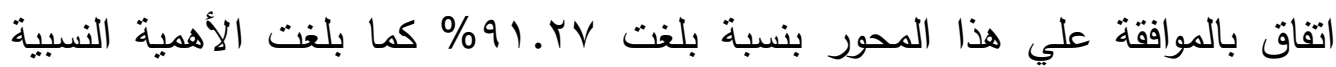

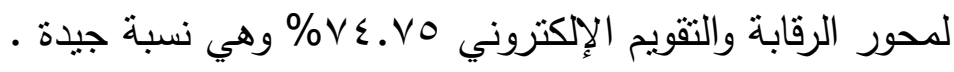

يساعد تطبيق الإدارة الإلكترونية في المدارس بتوفير الخطط الإدارية البديلة، وكيفية التعامل مع الأزمات الإدارية والبيئية المستجدة التي تواجه الإدارة بشكل مفاجئ . إن استخدام الإدارة الإلكترونية يساعد علي التخفيف من الأعباء الإدارية المختلفة في المؤسسات التعليمية مما بساعد علي تطوير الأداء الإداري. تساعد الإدارة الإلكترونية في إكساب الإداريين العديد من الخبرات الإدارية المتطورة والتي تتواكب مع متطلبات العصر ، وتحدياته. تشاهم الإدارة الإلكترونية في توظيف الموارد البشرية والمادية بشكل أفضل مما يساعد علي تطوير الأداء الإداري للمدرسة . تلعب الإدارة الإلكترونية دورًا هام في إنجاز الاعمال في وقت أقل منها في الإدارة النمطية، كما نوفر علي العاملين والمستقيدين من الخدمة عناء الإنتقال عبر الإدارات لإنجاز معاملتهم، وما يشعرهم بالراحة والسرعة والدقة في الحصول علي ما يحتاجونه من معاملاتهم في أسرع وقت وبأقل مجهود، وما يساعد علي تطوير الأداء الإداري للمدرسة. 


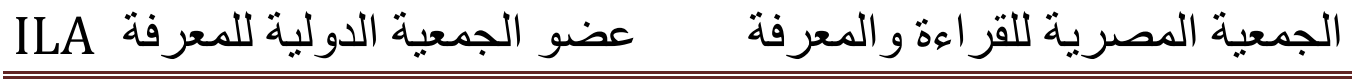

يساعد استخدام الإدارة الإلكترونية القيادات التعليمية التميز بالدقة في إنجاز المعاملات الخاصة بالمستقبدين من الخدمة لحصولهم علي الخدمة المطلوبة من قبلهم بسرعة ودقة، وموثقة إلكترونيا بتاريخ وبتوقيت ارسال الطلب وتاريخه، وتوقيت وتاريخ إنجاز المعاملة وإرساله إلي المستقيد مما يحسن الأداء الإداري للمدرسة . . تساهم الإدارة الإككترونية في تحسين مستوى الخدمة المقدمة للطلاب من قبل إدارة شؤون الطلاب لاعتمادها علي العمل القائم علي التنظيم الإكتروني الذي يسهل عملية الإدخال والحفظ والتخزين والاسترجاع في بيئة إلكترونية مؤسسة وسريعة ودقيقة، مما يساعد في إنجاز المعاملات الخاصة بالطلاب بشكل أسرع علي جعل إدارة المدرسة جاذبة للطلاب الجدد.

تساعد الإدارة الإلكترونية في كسر حاجز الروتين في إجراءات المعاملات المختلفة تسهم الإدارة الإكترونية في تتظيم الاجتماعات التعليمية الافتراضية إلكترونيا، مما يوفر الوقت في تتقل القيادات التعليمية لمكان واحد، وبقائهم في مكانتهم لمباشرة أعمالهم، والمشاركة في الاجتماعات الافتراضية بالإضافة إلي استخدام شبكات التواصل الاجتماعي، مما يوفر الوقت والجهد المبذول في التتقل والانتظار لأعضاء مجلس الإدارة، وتعطيل أعمالهم لحضور المشكلات اليومية في الوزارة . تلعب الإدارة الإلكترونية دورًا هاما في توفير نظام للأرشفة الإكترونية للبيانات الخاصة بمقدمة الخدمة، ومتلقي الخدمة، تقوم علي إدخال البيانات، وحفظها، واسترجاعها في أسرع وقت، وبشكل منظم في بيئة إلكترونية. ثانيا - توصيات ومقترحات الاراسة: بناء علي النتائج التي أسفرت عنها الدراسة والتي من أهمها يوصي الباحث بما يلي: 


\section{الجمعية المصرية للقر اعة والمعرفة عضو الجمعية الدولية للمعرفة ILA}

ضرورة تطبيق الأساليب الإدارية الحديثة في إدارة المدارس للحد من المشكلات

الإدارية وتطوير الأداء الإداري للقيادات التعليمية .

العمل علي تتظيم برامج تدريبية في الإدارة الإلكترونية لمديري المدارس

الأخذ بمبدأ التدريب المستمر في الإدارة الإكترونية لمديري المدارس بغض النظر

عن مؤهلات المديرين حيث أوضحث الدراسة أنه لا توجد فروق بين المؤهلات المختلفة، وبالتالي تحتاج هذه المؤهلات إلي هذه البرامج التدربيية لتطوير الأداء الإداري للقيادات التعليمية في المدارس •

إجراء المزيد من الدراسات حول الإدارة في المدارس للتعرف علي مدى تطبيقها

للإدارة الإلكترونية، لتطوير الأداء الإداري بالمدارس. 


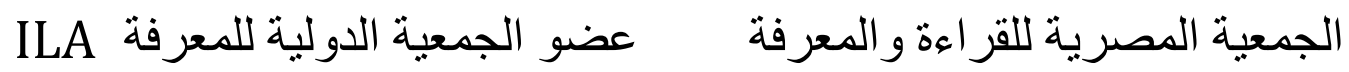

\section{قائمة المراجع

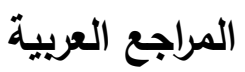

l. إبراهيم، حسام الدين السيد محمد (·.Y.Y). درجة ممارسة استراتيجيات إدارة

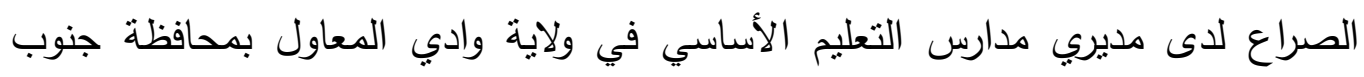

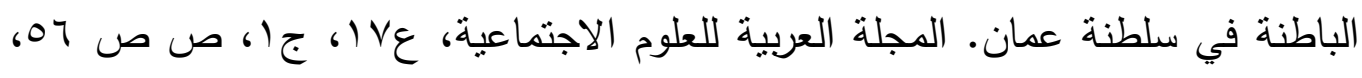
.1,

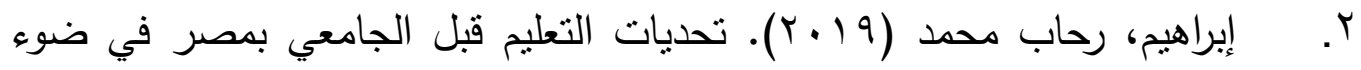

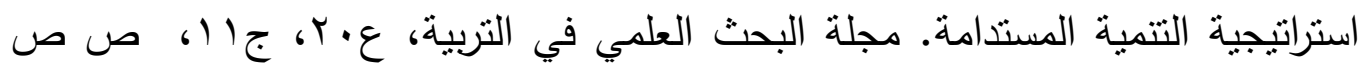
$\varepsilon \cdot \Lambda-r \wedge q$

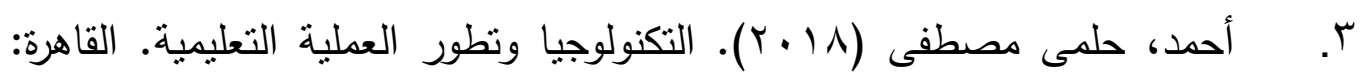

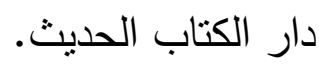

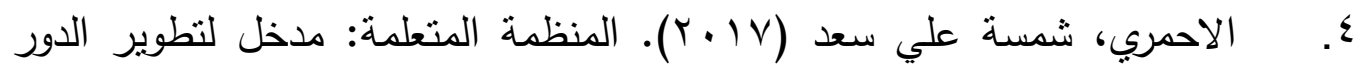
القيادي في المدارس.

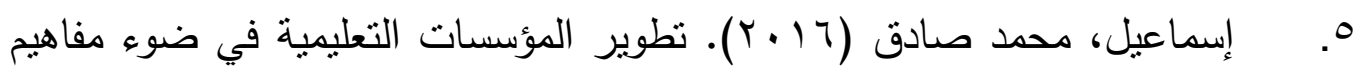
الجودة الثاملة. القاهرة: المجموعة العربية للتثريب والنشر . T. الاسناوي، جال فاروق احمد. (·r.r). الادارة الالكترونية. دسوق: دار العلم

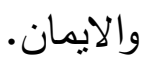

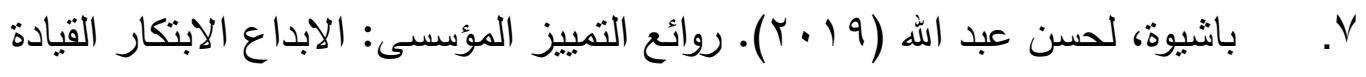

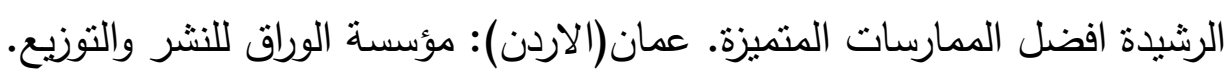




\section{الجمعية المصرية للقر اءة والمعرفة عضو الجمعية الدولية للمعرفة}

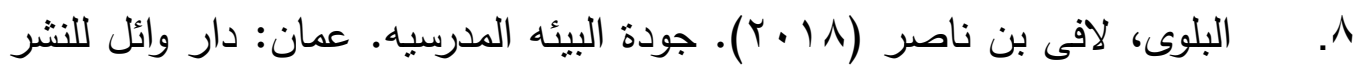
والتوزيع.

9 9. تمام، شادية عبدالحليم (19 (r). تقويم الأداء التدريسي لمعلم التعليم العالي. المنصورة : المكتبة العصرية للنشر والتوزيع.

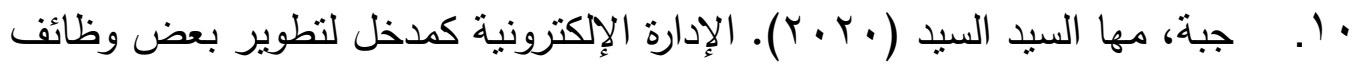

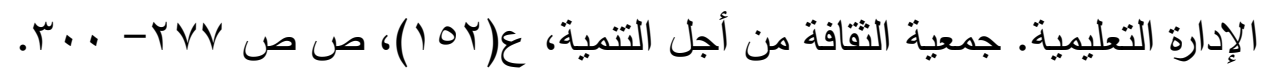

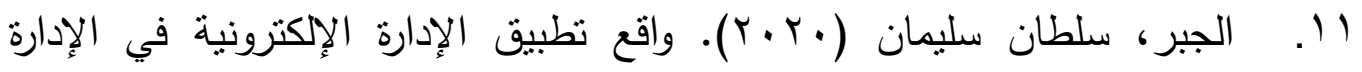

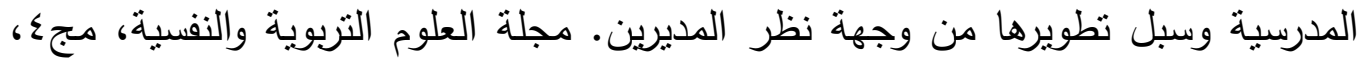
ع ع 1 ، ص ص :11

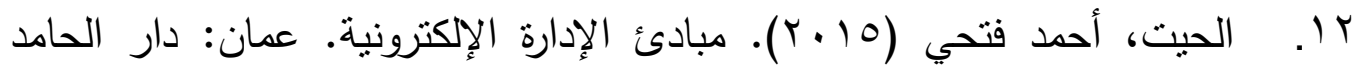
للنشر والتوزيع.

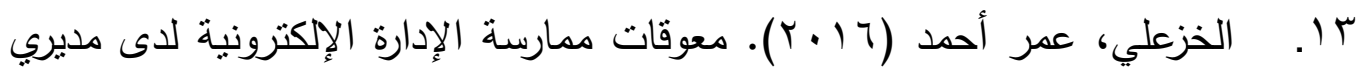
مدارس التربية والتعليم في لواء الرمثا. رساله ماجستير، كلية العلوم التربوية جامعة آل البيت. ع ا. . الخولي، محمد أحمد. (9 (1). منهجيات التميز لتطوبر الأداء المؤسسي. القاهرة: المنظمة العربية للتنمية الإدارية. 10. الرباط، بهيرة شفيق إبراهيم. (T ( • ( ). الإدارة التعليمية والمدرسية. الرياض: دار

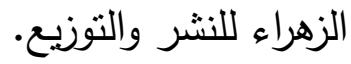

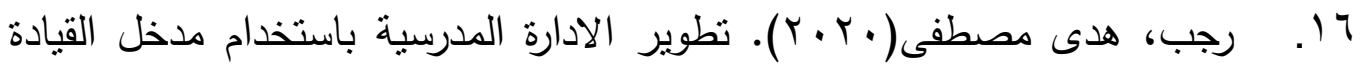
والحوكمة. دسوق: دار العلم والايمان للنشر والتوزيع. 


\section{الجمعية المصرية للقر اءة والمعرفة عضو الجمعية الدولية للمعرفة}

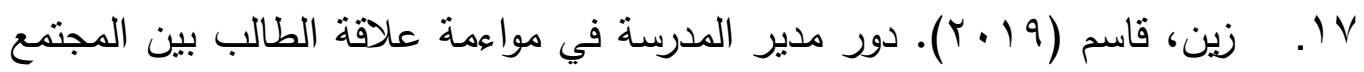
المحلى والمدرسة المهنية الرسمية: المدارس المهنية الرسمية في قضاء بنت جبيل نموذجا. جامعة الجنان - مركز البحث العلمي.

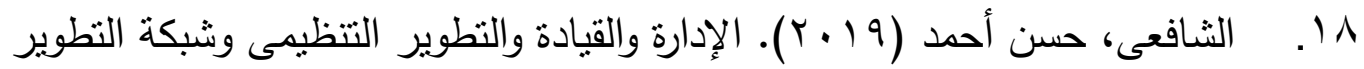
التتظيمى فى الإدارة التربوية التعليمية. الإسكندرية: مؤسسة عالم الرياضة.

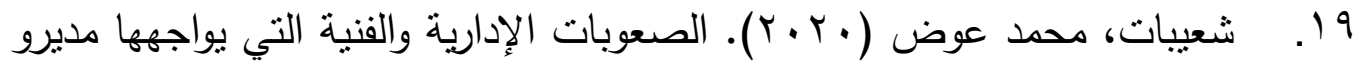
المدارس الحكومية في فلسطين. مجلة جامعة النجاح للأبحاث - العلوم الإنسانية ،

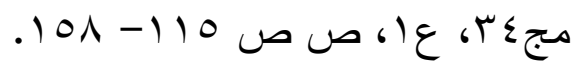

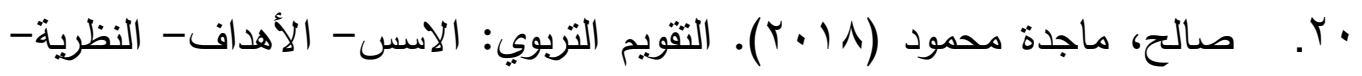
التطبيق. الاسكندرية: دار المعرفة الجامعية.

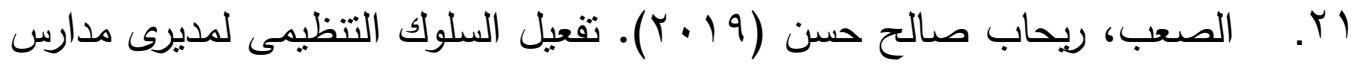
التعليم العام على ضوء الاتجاهات الحديثة فى الإدارة المدرسية. مجلة القراءة والمعرفة ،

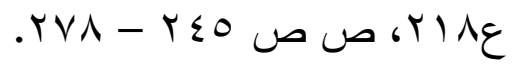
r.r. الطيطي، محمد عبد الإله (10 (10). واقع الإدارة الإلكترونية في تحقيق الإبداع الإداري في الجامعات الفلسطينية من وجهة نظر أعضاء هيئة التذريس والإداربين فيها.

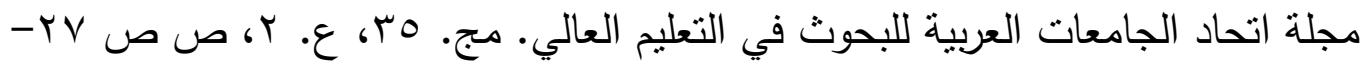

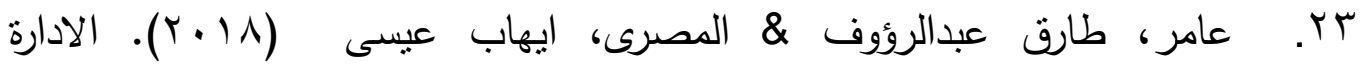
الالكترونية. القاهرة: موسسة طيبة للنشر والتوزيع. 


\section{الجمعية المصرية للقر اءة والمعرفة عضو الجمعية الدولية للمعرفة}

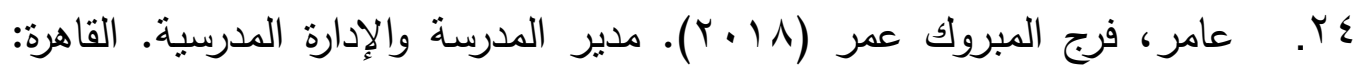

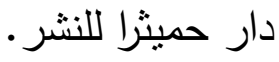

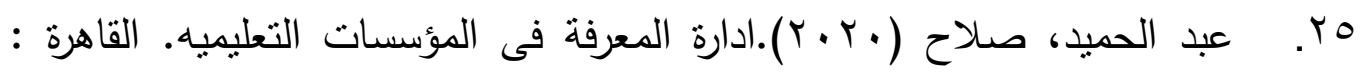
جامعة القاهرة. Tr. العجمي، كروز تراحيب (Y V). الاتجاهات المعاصرة في الإدارة المدرسية. القاهرة: دار الفكر العربي. rV والتطبيق. الأردن: دار الثروق للنشر والتوزيع.

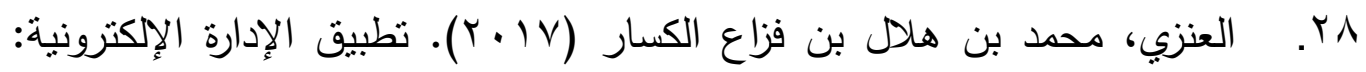
المفهوم -المزايا-المعوقات. المملكة العربية السعودية، الرياض: دار الكتاب الجامعي للنشر والتوزيع.

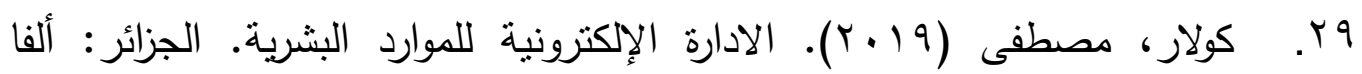
للوثائق. •r. . مرزوق، فاروق جعفر عبدالحكيم (·r.r). التعليم وريادة الأعمال: أطر نظرية وتجارب عالمية. القاهرة: دار النهضة العربية.

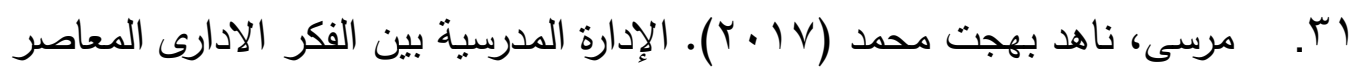
ومعايير جودة التعليم والاعتماد. القاهرة: مكتبة الانجلو المصرية.

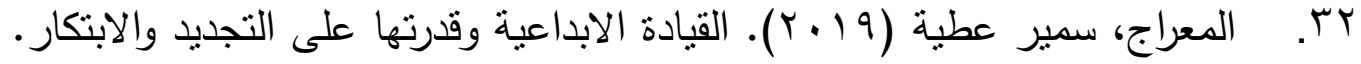
دسوق: دار العلم والايمان للنشر والتوزيع. 


\section{الجمعية المصرية للقر اعة والمعرفة عضو الجمعية الدولية للمعرفة ILA}

rس. المولى، يوسف (9 (ب). مهارات الإدارة : المدرسية والتربوية. عمان: دار الراية للنشر والتوزيع.

ع ז. نبيلة، عدنان (9 (ب). ضغوط العمل والاداء الوظيفى. عمان(الاردن) : مركز

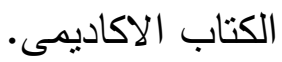

هب. نمر، محمد سعيد (1) (r). الإتجاهات الحديثة والتكنولوجيا في الإدارة العامة: الحكومة الالكترونية. عمان: زمزم ناشرون وموزعون. צr. هنط، عصام محمود حسن. (9 (Y). ادارة الابتكار والنظوير للمنظمات الحديثة. دسوق: دار العلم والايمان للنشر والتوزيع.

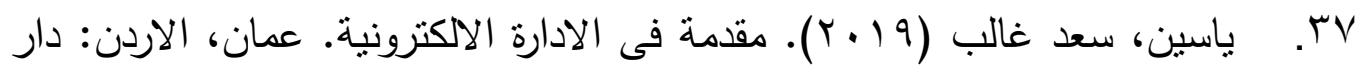
اليازورى العلمية للنشر والتوزيع. 


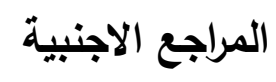

1. Alan B. Albarran (2016). Management of Electronic and Digital Media (Cengage Series in Communication Arts. Boston: Cengage Learning.

2. ALKHSABAH, Mohammad Ali Ibrahim (2017). Reality of Use of Electronic Management and its Impact on Job Performance in Tafila Technical University. International Journal of Academic Research in Accounting, Finance and Management Sciences Vol. 7, No.1, pp. 329-341.

3. atrill, peter (2017). financial management for decision makers. united kingdo: pearson education limited.

4. Atulomuah, B.,C. (2011). Perceived records management decision making among university administrators in Nigeria. Library Philosophy and Practice (e-jour Paper 541.

5. Fritz, Beane (2015). The relationship between the practice of strategic management and development of teachers' performance. Journal of research and development in education, 56 (3): 21 -42.

6. Kowalski, Theodore J (2012). Case studies on educational administration. Boston: Pearson.

7. Marutha, Ngoako S \& Ngulube, Patrick (2012). Electronic records management in the public health sector of the Limpopo province in South Africa. 39 Journal of the South African Society of Archivists, Vol. 45, pp. 39- 67.

8. Oyedemi, O (2015). ICT and effective school management, administrator perspective. Paper presented at the world congress on engineering(WCE 1- 3 July 2015, London, U.K.

9. Panigrahi, Manas Ranjan (2018). School administration and educational planning. New Delhi: A. P. H. publishing corporation. 
10. Rawahneh, A., O. (2013). Effect of quality of HRM on Performance of employees of Jordan Telecom, unpublished master thesis, Middle East University, Ammaan, Jordan.

11. Rehaf A. Madani (2020). Analysis of Educational Quality, a Goal of Education for All Policy. Higher Education Studies 9 (1): pp. 100-109.

12. Robinson, Susan (2012). School and system leadership: changing roles for primary headteachers. New York: Continuum.

13. Shakuna, Khairi Saleh\& Mohamad, Norhisham\& Ali, Asbi B. (2020). The Effect of School Administration and Educational Supervision on Teachers teaching performance: Training Programs as a Mediator Variable. Asian Social Science, Vol. 12, No. 10; 2016 pp. 257-272. 